Article

\title{
Feasibility Analysis and Performance Evaluation and Optimization of a DXSAHP Water Heater Based on the Thermal Capacity of the System: A Case Study
}

\author{
Jorge E. De León-Ruiz ${ }^{1, *}$, Ignacio Carvajal-Mariscal ${ }^{1}$ and Antonin Ponsich ${ }^{2}$ \\ 1 Instituto Politécnico Nacional, ESIME-UPALM, CDMX 07738, Mexico; icarvajal@ipn.mx \\ 2 Departamento de Sistemas, Universidad Autónoma Metropolitana, Azcapotzalco, CDMX 02200, Mexico; \\ aspo@azc.uam.mx \\ * Correspondence: jedeleonr@gmail.com; Tel.: +52-55-5729-6000 (ext. 54754)
}

Received: 26 September 2019; Accepted: 11 October 2019; Published: 14 October 2019

\begin{abstract}
The present work conducts an evaluation of the feasibility and the overall performance and consequent optimization of a direct expansion solar assisted heat pump (DXSAHP) employed for domestic water heating. For the study conducted R134a, R404A, R407C and R410A working fluids were evaluated as well as the use of four, six and eight flat-plate solar collectors and a worktime ranging from 1 to $6 \mathrm{~h}$. The case study is based in Mexico City with a $300 \mathrm{~L}$ container and a hot water outlet temperature of $51^{\circ} \mathrm{C}$. The paper introduces a new evaluation criterion based on the thermal capacity and all the evaluations conducted throughout this research revolve around this performance metric. The results show that, the system would require at least $4 \mathrm{~h}$ of operation to achieve the outlet temperature. Additionally, it was found that the R410A refrigerant has the best heat transfer properties; with an average condensation heat rate of $6.31 \mathrm{~kW}$, followed by the R407C with $5.72 \mathrm{~kW}$, the R404A with $5.42 \mathrm{~kW}$ and the R134a with $5.18 \mathrm{~kW}$. Diversely, the R134a refrigerant requires $0.402 \mathrm{~kW}$ of compression work, $62 \%$ less than the R410A, which requires $1.06 \mathrm{~kW}$. Consequently, R134a delivers the highest COP, which ranges from 7 to 14, followed by the R407C and R404A refrigerants, which present a similar behaviour between them, with COP ranging from 5 to 9 and 4 to 8 , respectively, and finally the R410A, achieving the lowest COP, ranging from 3.5 to 6.5. Moreover, it was found that the R134a presents a higher dispersion regarding the energy exchange rate, which reveals that it is the fluid most susceptible to external factors, such as the weather. Contrarily, the remaining refrigerants present a more consistent performance. Finally, the optimization revealed that the R407C refrigerant is the most suitable given that it requires $20 \%$ less compression work than the R404A. This provides the heat pump system with a steadier behaviour, a COP ranging from 7 to $8,30 \%$ higher than R410A, a worktime decrease of $1.5 \mathrm{~h}$ and heat transfer area of 5.5 flat-plate solar collectors, equivalent to a $31 \%$ reduction, both compared to R134a.
\end{abstract}

Keywords: heat pump system; optimization; thermal capacity; water heating; statistical analysis

\section{Introduction}

In the last decades, the subject of efficient use of energy has become of great interest, for economic as well as environmental reasons. The increasing demand of petroleum-based products and the consequent increase in fuel prices in the global market and issues caused by overexploitation of natural resources, have led to an increase in research and development of new technologies or alternatives to harness renewable energies, as well as new policies regarding energy savings and its efficient use [1,2].

The result of these policies is represented by the progressive measures implemented around the world, where the government and a variety of institutions and associations offer subsidies or economic 
support to encourage the population to migrate to an energy matrix based on renewable energies. As a result, it is common to find solar thermal and photovoltaic installations, in both domestic and commercial sectors, which in some cases contribute to the generation of more than a quarter of the total energy consumption [3].

Several studies have been conducted regarding the design and operation of these technologies, particularly heat pump-based appliances [4-10]. Characterized by the variety of the existing options and the satisfactory results yielded, their availability and utilization has proliferated [11-14].

\subsection{Optimization of Energy Processes}

Recently, the focus regarding energy processes, particularly heat transfer or generation systems, has shifted to the implementation of optimization techniques, aimed to improve the performance of the heat pump-based systems, which has led to several different approaches being employed and reported.

First, the thermoeconomic analysis is one of the most employed techniques; a comprehensive perspective with intrinsic and rather moderate optimization capabilities, based on evaluating the irreversibilities of the cycle and the effect these exert on the overall performance of the system in terms of either the exergy destruction or the entropy minimization. An example of the implementation and benefit of this approach applied to heat pump systems is presented in the research conducted by Cruz-Fonticiella et al. [15] where they focus on the relation between the irreversibilities and the structural configuration of the heat pump. They obtained a database that allowed them to assess the performance of each component, concluding that a long-term cost-optimal performance is achieved when the heat exchangers are designed and fitted according to the capacity of the system in terms of the temperature difference of the condenser and the mean temperature of the evaporator. Similarly, Torres-Reyes and Cervantes de Gortari [16] modelled a solar-assisted heat pump based on the irreversibilities. They obtained the relation between the heat transfer capacity of the evaporator and the condenser, based on the exergy efficiency, a designated COP and a maximum heating load. They obtained the optimal thermal performance in terms of the external conductance and attributed the variations on the adjustment of the model regarding the experimental setup to the climate conditions. Kalogirou et al. [17] conducted a review on the exergy analysis of solar thermal processes. They found that the solar collectors were the component with the highest exergy destruction rate in solar heating and air conditioning devices, hence, the exergy analysis could be a tool used to provide insight into the optimal selection of surface types, geometries, and collector dimensions. Nonetheless, they remark that it is important to evaluate the performance of the collectors throughout a wide range of conditions, mainly to determine the effect the atmospheric conditions exert over the device. They conclude that this as an indispensable methodology to evaluate and compare setups in order to optimize performance based on their specific attributes, characteristics and operation parameters.

As stated before, a thermoeconomic analysis is an optimization method considered relatively effective since it broadly reflects an improvement on both the performance of the cycle as well as its operation costs. However, this approach is rather constrained since, depending on the model proposed, it does not always accounts for the complete set of variables involved in the operation of the system, and, since these systems do not generate a work output, the interpretation of the effective energy is left, to some extent, ambiguous. Hence, the results yielded are limited by the exergy efficiency computation and the optimization of the cycle is achieved by comparing setups rather than by a categorical output.

Diversely, several researchers have instead developed integral models of the processes involved and often combined it with different mathematical and numerical methods in order to optimize the performance of the system based on either maximization or minimization of certain variables, mainly the COP.

Guo et al. [18] applied soft optimization to the model proposed in order to improve performance in terms of structural and operational patterns. They obtained that, for their setup, satisfactory COP is obtained when: the heat transfer area is between 6 and $6.5 \mathrm{~m}^{2}$; the optimal start up time is between 12:00 and 14:00 and the setting water temperature is above $46^{\circ} \mathrm{C}$ during summer and $50^{\circ} \mathrm{C}$ for the remaining 
seasons. Similarly, Sánta et al. [19] developed a model solved using Runge-Kutta and Adams-Moulton methods for numerical solution. Applying soft optimization to determine the maximum coefficient of performance given a determined thermal load they obtained that, for their setup, a maximum COP of 5.42 was achievable for a $3.5 \mathrm{~kW}$ heat demand. Furthermore, Potočnik et al. [20] propose an alternative approach to the offline optimization of weather-depending heating curves in order to maximize indoor thermal comfort for each parametrization case. They found that this approach does not require daily heating regimes computation, that it generates optimized heating curves and furthermore that the considerations of the atmospheric conditions during the optimization process results in a positive contribution towards the improvement of the indoor thermal comfort. Additionally, Bell and Lemort [21] applied soft optimization to improve performance of the heat pump given a fixed evaporator surface temperature finding that R152a is good working fluid for the system proposed given its high efficiency and reasonable compressor sizing. Furthermore, the COP of the system can be maximized by setting the maximum evaporator surface temperature to the maximum allowed and that when maximum electrical component temperature condition is imposed the best performance is achieved when both ambient temperature and evaporator load are low. Mehrpooya et al. [22] also employed soft optimization and studied the resulting optimal design of a combined solar and ground source heat pump system for greenhouse application. They obtained that the optimum performance when operating with both heat absorption loops and a suitable working fluid reaches 4.14. Diversely, when adding a heat exchanger after the storage tank and using the best working fluid available, even though COP increases to 4.33 , the increase of both the initial and operational costs alongside an increase in the auxiliary energy needed cause a decrease on the efficiency of the system. Concluding that the most important parameters in choosing an optimized system are: minimum and maximum $\mathrm{COP}$ when maximum heating load is required; auxiliary energy supplied by the additional heaters and the trade-off between costs and performance. Alabdulkareem et al. [23] using a $10.55 \mathrm{~kW}$ heat pump system conducted a simulation and posterior soft optimization to find suitable alternatives for the R410A refrigerant based on a low GWP and a rather moderate structural pattern criteria. Regarding the working fluid, they obtained that R32 is superior to R410A in terms of cooling and heating capacities; L41 is superior to R410A in terms of COP and D2Y60 is superior to R410A in terms of compressor discharge temperature. Furthermore, for all the refrigerants a significant charge reduction was observed. Additionally, the result of the structural analysis showed that three improvements could be made: installing a thermal expansion device for L41 so that superheating superheating could be obtained, enhancing heating results by $11 \%$; using a large-capacity displacement compressor when employing D2Y60 to increase cooling capacity and employing a suction line heat exchanger to increase the COP.

Calise et al. [24] analysed the performance in terms of economic profitability of a PVT heat pump system, using the generalized search method as optimization technique. They obtained that this optimal point is achieved hen employing a collector area of $24.25 \mathrm{~m}^{2}$ obtaining a simple pay back, SPB, of 14.38 years, and that the energetic and economic performance is better in localities with greater energy availability. To further expand their analysis, they employed a design of experiments approach, $\mathrm{DOE}$, to minimize the simple pay back and maximize the primary energy savings [25] the results show a decrease on the SPB form 5.36 to 3.25 years and an increase of energy savings from 2.43 to $7.71 \mathrm{kWh} /$ year. Similarly, Fang et al. [26] developed a predictive model based on performance optimization employing also the DOE approach, evaluating the effect the evaporator air inlet temperature, the air velocity and the compressor frequency have when maximizing COP. The results show that the last two have a more significant effect than the evaporator air inlet temperature, and that the most important design factor was the compressor frequency having an effect on both the cooling capacity and the energy consumption of the compressor.

Alimohammadisagvand et al. [27] also optimized the performance of a heat pump-based system using predictive models based on demand response algorithms. Results show $12 \%$ and $10 \%$ improvements in maximum total delivered energy and costs savings respectively, and they found 
that an overall minimum life cycle cost occurs when $60^{\circ} \mathrm{C}$ is set as the temperature set point with a $0.3 \mathrm{~m}^{3}$ storage tank.

Li and Kao [28] implemented a Taguchi optimization for two configurations of solar thermal heat pumps, single and dual tank, under five different climatic conditions to determine optimal operating parameters, their contribution and payback period. They obtained that each parameter had a varying level of effect on performance, depending on the location, and attributed this to the interplay between climatic conditions and technical features of the systems. They also found that the flow rate of the heat pump and the flow rate of the solar collector were the most influential parameters for the single and dual tank configurations respectively, regardless of the location. Furthermore, they concluded that the dual tank system is less susceptible to the atmospheric conditions and is the more economical regarding the operational cost, nonetheless, the single tank setup offers a shorter payback period.

Based on the information presented so far, it is evident that heat pump-based appliances are rather complex systems where a considerable amount of parameters are involved and intertwined. Variables related to the atmospheric conditions, over which no control can be exerted, as well as the operation parameters, which do not respond equally to maximization or minimization given an implicit trade-off within the magnitude of this variables and the overall performance. Examples of this trade-off are:

- The increase of the solar collector area, which increases the energy absorbed by the evaporator, would also increase the surface temperature triggering a back loss via convection phenomena, ultimately decreasing the COP.

- The use of a refrigerant with higher heat capacity that, in most cases, comes associated with a higher density; this would not only increase the heat absorption but also the compression work needed to transport the refrigerant, which consequently would decrease the overall performance of the HP system.

\subsection{Multi-Objective Optimization}

In order to address this, lately, researchers have resorted to multi-objective optimization techniques as a mean for obtaining the best possible combination of factors with the minimum level of compromise between impinging variables. Kalogirou [29] proposes the implementation of the artificial neural networks, ANN, as a multi-objective optimization technique in order to analyse complex problems proposed by energy processes. Using them as a forecast tool it is possible to estimate and optimize the performance of the system based on an efficient energy management criterion, reducing consumption and thus increasing performance. Similarly, Mohanraj et al. [30] coincide in the fact that this particular technique can be successfully used in refrigeration, air-conditioning and heat pump systems, suggesting the hybridization of ANN with other expert systems and using them to develop simplified correlations for predicting optimized performance.

Bellos and Tzivanidis [31] using multi-objective optimization aimed to improve the performance of a heat pump-based cogeneration system in terms of both the maximum heat and net electricity production using seven different refrigerants. They obtained that for the setup proposed the best two refrigerants were R32 followed by the R1234yf with $4.331 \mathrm{~kW}$ and $0.537 \mathrm{~kW}$ of heat and electricity production respectively. With the R404A being the fluid with the maximum heat production and the R245fa with the maximum electricity production.

Khorasaninejad and Hajabdollahi [32] implemented a multi-objective optimization based on a particle swarm algorithm alongside a thermoeconomic assessment to improve the performance of a solar-assisted heat pump using the COP and the total annual cost, TAC and five different working fluids. The results showed that the R245fa presents a reduction of TAC of $15.22 \%, 21.18 \%, 22.31 \%$ and $44.66 \%$ as well as an increase of COP of $26.77 \%, 30.92 \%, 34.31 \%$ and $48.12 \%$ compared to the R134a, $\mathrm{R} 123, \mathrm{R} 22$, and R407C, respectively. Additionally, they found that the R245fa refrigerant requires the lowest storage capacity, condenser subcooling, evaporator superheating, fuel consumption and operational as well as environmental costs, compared with the remaining refrigerants. 
Lee et al. [33] implemented a genetic algorithm to optimize both the seasonal COP and EER of a heat pump system, based on the compressor frequency as well as both indoor and outdoor airflow rate. The optimization of the three operating parameters yielded increases of $7 \%$ and $21.4 \%$ for COP and EER respectively. Moreover, the optimum compressor volume was obtained which increased COP in $3.8 \%$ and EER in $1.1 \%$. Similarly, Starke et al. [34] also implemented a genetic algorithm to optimize the performance of the heat pump when operating in five different cities and based on the annualized life cycle cost, ALCC, and the thermal comfort level, assessing the high trade-off between a specific level of comfort and the cost it would entail. The results show that the ALCC ranges between 500 and 3000 US\$ with comfort levels ranging between $10 \%$ and $80 \%$ depending on the location.

\subsection{Aim of the Investigation}

The present work is carried out within the framework of the National Development Plan; a joint effort between the IEA and the Mexican government to move away from fossil fuels and at the same time, lay the foundation for a transition to a more sustainable energy consumption model. This initiative established a goal of gradually increasing the generation of energy through renewable sources up to $35 \%$ by 2024 , which is equivalent to an annual increase of $3 \%$ [35-38]. The application is based on an average household energy consumption rate, in the metropolitan area of Mexico City in Central Mexico. The assessment makes use of the corresponding atmospheric data [39]. The household requires a volume of water of $300 \mathrm{~L}$ at an outlet temperature of $51{ }^{\circ} \mathrm{C}$. More details about the case study are given in Section 3.

In this study, a direct-expansion solar-assisted heat pump is used as a mean to fulfil the demand of domestic water heating, DWH, and whether the demand is met or not is determined based on different operation conditions. The overall analysis of the energy exchange rate of the system is presented, considering various scenarios regarding configuration, i.e., number of solar collectors, working fluid, and both geographic as well as temporal references. The feasibility of installation, performance evaluation and subsequent optimization are then carried out in terms of a new relative efficiency previously introduced, known as Thermal Capacity, $\tau_{C},[40,41]$ which was developed to assess both the efficiency and overall effectiveness of the system based on a supply-and-demand criterion. This performance metric complements the already existing ones, particularly COP, and helps determine if not only the HP system fulfils the thermal demand, but also the degree at which said demand is met.

This paper discusses the performance assessment and optimization, but focuses mainly on introducing new modelling/evaluation criteria, based on the thermal capacity and the consequent statistical analysis of the optimization variables, to determine the effect the aforementioned factors exert upon the energy transfer capabilities of the heat pump system as a whole. Therefore, the goal is to propose this methodology as a mean to evaluate different HP-based systems, illustrating the impact the thermal capacity has when conducting these types of assessments; the information it provides regarding the design and dimensioning and thus proposing it as a starting point for the implementation of any optimization technique.

The presented operation scenarios include, working with four, six and eight flat-plate solar collectors, during one to six hours and using R134a, R404A, R407C and R410A as working fluids. These conditions are evaluated throughout a year and the changes regarding the atmospheric conditions are accounted for, based on published historical data; testing the energy exchange rate of the system with different magnitudes of ambient temperature, wind speed, relative humidity and normal beam radiation.

In this research a genetic algorithm, GA, a well-known and largely employed optimization technique is proposed as a mean to obtain the best configuration available based on the weather, design and operation conditions. Furthermore, a thorough post-processing stage based on statistical inference and probability density estimation complements the analysis and is used to identify the tendencies and quantify the effect of the optimization variables, thus illustrating the possible improvements in order to increase performance. 
This paper is structured as follows: In Section 2, the layout of the thermal modelling is described and the new relative efficiency is introduced, as well as the system specifications including the dimensions and configuration of the devices that comprise the proposed DXSAHP setup. The case study is presented in Section 3 where the operation conditions are described based on the desired properties of the product as well as the atmospheric, geographic and temporal parameters of the region. The analysis of the feasibility study, the performance assessment and the consequent optimization are discussed in Section 4. Finally, this paper concludes in Section 5 with a brief summary of the findings and perspective for future work.

\section{System Modelling and Description}

The research reported in this paper employs a model developed for this particular application, as well as an alternative evaluation criteria based on a new relative efficiency, both previously published by De León and Carvajal [40,41], where fully detailed explanations are provided.

\subsection{Thermal Modelling}

The thermal modelling of the system is based on the solution of an algorithm programmed using Engineering Equation Solver, EES, to determine the thermophysical properties of the fluids and materials as well as the thermodynamic state properties of the refrigerant based on the processes of the heat pump cycle.

Equations (1)-(9) model the radiation and convection heat transfer mechanisms, relating the environmental variables with the total thermal energy absorbed by the collectors-evaporators [42-49]:

$$
\begin{aligned}
& \dot{Q}_{\sigma, T}=G_{T} A_{\text {Coll }} \chi_{F} \\
& G_{T}=\left[G_{B}+\left(G_{D} A_{S}\right)\right] R_{B} \\
& +\left[G_{D}\left(1-A_{S}\right)\left(\frac{1-\cos (\beta)}{2}\right)\right]\left[1+\left(\sqrt{\frac{G_{B}}{\left(G_{B}+G_{D}\right)}}\right) \operatorname{sen}^{3}\left(\frac{\beta}{2}\right)\right] \\
& +\left(G_{B}+G_{D}\right) \rho_{S}\left(\frac{1-\cos (\beta)}{2}\right) \\
& \dot{Q}_{h}=\bar{h}_{C} A_{\text {Coll }} \chi_{F}\left(T_{\infty}-T_{S}\right) \\
& \bar{h}_{C}=\frac{\overline{N u} k_{\infty}}{L_{C}} \\
& \overline{N u}_{f, \text { sup }}=\frac{0.3387 \operatorname{Re}_{L}{ }^{1 / 2} \operatorname{Pr}_{\infty}{ }^{1 / 3}}{\left[1+\left(\frac{0.0468}{P r}\right)^{\frac{2}{3}}\right]^{1 / 4}} \\
& \overline{N u}_{n, \text { sup }}=1+1.44\left[\left(1-\frac{1708}{R a \cos (\beta)}\right)\left(1(1708)\left(\frac{\operatorname{sen}^{1.6}(\beta)}{R a \cos (\beta)}\right)\right)\left(\left[\frac{\operatorname{Ra} \cos (\beta)}{5830}\right]^{\frac{1}{3}}-1\right)\right] \\
& \overline{N u}_{n, \text { inf }}=0.56(\operatorname{Gr} \operatorname{Pr} \cos (\beta))^{\frac{1}{4}} \\
& \dot{Q}_{h, T}=\dot{Q}_{h}+\dot{Q}_{h, i n f} \\
& \dot{Q}_{S C F}=\dot{Q}_{\sigma, t}+\dot{Q}_{h, t}
\end{aligned}
$$

Then the vapour compression cycle is modelled through a first law of thermodynamics approach, Equations (10)-(12) quantifying the thermal energy that the refrigerant is able to transfer [50,51]:

$$
\dot{Q}_{\text {Evap }-S A}=\dot{Q}_{E}+\dot{Q}_{S C F}
$$




$$
\begin{gathered}
\dot{Q}_{\text {Cond-SA }}=\dot{Q}_{E-S A}+\dot{W}_{\text {Comp }} \\
\operatorname{COP}_{S A}=\frac{\dot{Q}_{\text {Cond-SA }}}{\dot{W}_{\text {Comp }}}
\end{gathered}
$$

Afterwards, the energy demanded by the water contained in the TSU is quantified, Equations (13)-(15):

$$
\begin{gathered}
\dot{q}_{V}=m_{H 2 O} C p_{H 2 O} \frac{\left(T_{O}-T_{i}\right)}{\Delta t} \\
\dot{q}_{L}=\frac{\left(T_{O}-T_{\infty}\right)}{R_{T}} \\
\dot{q}_{T}=\dot{q}_{V}+\dot{q}_{L}
\end{gathered}
$$

The proposed model determines the feasibility of installation of a heat pump-based system, as well as provides relevant data regarding the operation and performance of such system, employing 34 input variables. These variables, considering their nature, can be grouped into 3 particular sets that describe specific characteristics of the DXSAHP system and are structured as follows:

- $\quad$ System specifications. Presented in Table 1 , which includes the compressor capacity, $V_{D}$, rotation speed, $N_{C}$, and efficiency, $\eta_{C o m p}$, as well as the capacity, $V_{H 2 O}$ and geometry, $D_{T S U}, H_{T S U}, w_{\text {int }}, w_{\text {ins }}$, $w_{\text {ext }}$, of the thermal storage unit, the dimensions, $L_{\text {Evap }}, H_{\text {Evap }}, w_{\text {Evap }}$, inclinations, $\iota, l Z$, number, $N_{\text {Evap }}$ and the compensation factor, $\chi_{F}$, of the collectors-evaporators. Finally, this list includes the temperature gradients in the exchangers, $\Delta T_{C}, \Delta T_{E}$, the working fluid, worktime, $\Delta t$ and the water inlet and outlet temperatures, $T_{i}$ and $T_{O}$ respectively.

- Atmospheric and geographic conditions. Which include, atmospheric pressure, $P_{\infty}$, air

\begin{tabular}{|c|c|}
\hline Device & Characteristics \\
\hline Compressor & $\begin{array}{c}\text { Hermetic reciprocating } \\
\text { Volumetric displacement }=2.7505 \mathrm{~m}^{3} / \mathrm{h} \\
\text { Rotation speed }=3500 \mathrm{rpm} \\
\text { Compression efficiency }=0.95\end{array}$ \\
\hline $\begin{array}{c}\text { Thermal Storage } \\
\text { Unit }\end{array}$ & $\begin{array}{c}\text { Vertical cylinder with an immersed helical coil heat exchanger } \\
\text { Height }=1.10 \mathrm{~m} \\
\text { Diameter }=0.70 \mathrm{~m} \\
\text { AISI } 304 \text { internal sheet thickness }=0.0035 \mathrm{~m} \\
\text { Polyurethane insulation thickness }=0.08 \mathrm{~m} \\
\text { AISI } 304 \text { external sheet thickness }=0.0035 \mathrm{~m} \\
\text { Cold water inlet temperature }=\mathrm{T}_{\infty}-5^{\circ} \mathrm{C}\end{array}$ \\
\hline Collector/Evaporator & $\begin{array}{l}\text { Bare flat-plate heat exchanger with a capillary tube as an expansion device } \\
\text { Length }=0.80 \mathrm{~m} \\
\text { Width }=0.30 \mathrm{~m} \\
\text { Thickness }=0.001 \mathrm{~m} \\
\text { Horizontal inclination }=19^{\circ} \\
\text { Azimuth inclination }=0^{\circ} \\
\text { Compensation shape factor }=0.6 \\
\text { Number of collectors }=4-8\end{array}$ \\
\hline Working fluids & R134a, R404A, R407C, R410A \\
\hline
\end{tabular}
temperature, $T_{\infty}$, wind speed, $U_{\infty}$, direct normal radiation, $G_{B N}$, and relative humidity, $R H$ as well as the local and standard latitude and longitude, Lat ${ }_{\text {Local }}$, Lat $_{\text {Std }}$, Long $_{\text {Local }}$, Long $_{\text {Std }}$.

- Temporal reference. Which is function of the day, month and standard time.

Table 1. System technical/design specifications of the DXSAHP system. 
From these variables, the model proposed determines the dimensionless numbers, the convection heat transfer coefficients, the solar angles, the diffuse and the total solar radiation on a tilted surface as well as the thermophysical properties of the working fluid and as a result, six main output variables are obtained:

- Energy exchange rate. The total heat flow absorbed by the collectors, $\dot{Q}_{E}$, the heat flow yielded by the condenser, $\dot{Q}_{C}$, the compression work input, $\dot{W}_{C}$, and the total thermal demand, $\dot{q}_{T}$.

- Relative efficiencies. The coefficient of performance, COP, and the newly introduced, thermal capacity of the system, $\tau_{C}$.

These variables quantify the energy exchange and describe the performance of the DXSAHP in relation to both the surroundings as well as the volume of product to be heated based on the application for which the HP system was designed. A thorough description of the solution logic of the algorithm, as well as its validation is presented in a previously published research [40].

\subsection{Thermal Capacity as Relative Efficiency}

Furthermore, the study presented in this paper revolves around a concept known as thermal capacity, Equation (16), a relative efficiency which measures the capacity the heat pump has to increase the temperature of a determined quantity of substance, up to a desired outlet condition as a function of the condensation heat flow, $\dot{Q}_{C}$, and the heating load, $\dot{q}_{T}[41]$ :

$$
\tau_{C}=\frac{C O P}{E F} \frac{\frac{\dot{Q}_{\text {Cond }}}{\dot{W}_{\text {Comp }}}}{\frac{\dot{m}_{p} C p_{p, T_{i}}\left(T_{f}-T_{i}\right)}{\dot{W}_{\text {Comp }}}}=\frac{\dot{Q}_{\text {Cond }}}{\dot{q}_{T}} \rightarrow \tau_{C} \geq 1
$$

The newly proposed relative efficiency has proven to be useful to evaluate any heat pump system despite its configuration or application, as well as being complementary to the existing performance metrics, i.e., coefficient of performance and energy factor, contributing to a more comprehensive understanding of the operation and design of these systems. This contribution presents itself as an inherent reference point, setting a limit for the minimum heat supply needed to achieve and maintain the desired outlet condition, based on the total thermal load demanded by the volume of product.

As seen in Equation (1) a condition of $\tau_{C} \geq 1$ is always desired, ensuring that the HP transfers enough or more energy to the product than the required to reach the desired outlet condition. This standard imposes an operation scheme under which the system must always work, not only determining if the demand is fulfilled, but also measuring the quality of the performance to a degree where structural and operational changes can be made. A meticulous explanation and comprehensive evaluation regarding the application of this relative efficiency are both provided by De León and Carvajal [41].

Due to the conditional nature of the thermal capacity, in the work presented in this paper, this parameter is considered a starting point for the complete analysis conducted, since it secured an adequate performance without constraining the coefficient of performance, thus, obtaining solutions with the maximum COP available for that particular operation condition.

\subsection{System Description}

The proposed DXSAHP setup is shown in Figure 1. Heat from both sun and atmosphere is absorbed through radiation and convection mechanisms respectively by the heat collection field subsystem, which consists of four to eight parallel bare flat-plate solar collectors-evaporators. The heat is then transported to the condenser by the refrigerant circulating through the heat pump cycle, which has as its main components a reciprocating hermetic compressor and an expansion device, in addition to both heat exchangers. 


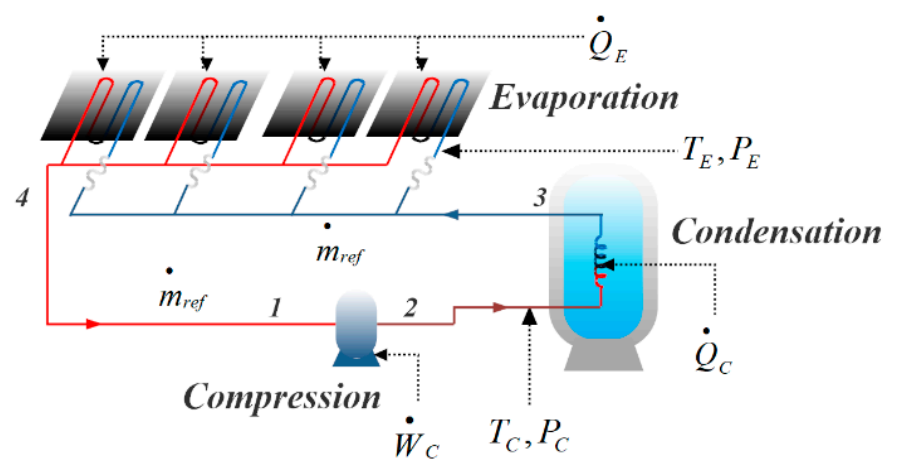

Figure 1. DXSAHP system diagram.

The refrigerant, which absorbs part of the heat that reaches the collectors-evaporators (process 4-1, Figure 1), changes its phase from liquid to superheated vapour before entering the compressor (process 1-2, Figure 1). Afterwards, it undergoes another phase change when the heat absorbed in the evaporator is yielded by the condenser to the cold water contained inside the thermal storage subsystem; subcooling the refrigerant (process 2-3, Figure 1). For this application, the thermal storage subsystem consists of an immersed coil heat exchanger installed inside an insulated tank that contains the water to be heated. The technical specifications of the system are listed in Table 1.

\section{Case Study}

The case study proposed is based on the average household energy/utilities consumption, with a $47 \%$ of the total destined to DHW production. An average $300 \mathrm{~L}$ container is employed for water storage, an average inlet water temperature ranging from $10^{\circ} \mathrm{C}$ to $15^{\circ} \mathrm{C}$ and a desired outlet temperature of $51^{\circ} \mathrm{C}$ are employed in the simulation and, given the average daily peak sun hours, the DXSAHP system operates from 1 to $6 \mathrm{~h}$.

To analyze the impact of the environmental conditions, information obtained through the Atmospheric Monitoring System [39] is employed. A 10-year period database was used to report the four parameters that describe the atmospheric conditions of Mexico City throughout the year (see Figure 2), where the average hourly measurements appear in yellow, while the daily mean is illustrated by a blue line.

The figure describes atmospheric conditions corresponding to a sub-humid climate where the average air temperature is higher during spring and lower during winter with averages of $20.11^{\circ} \mathrm{C}$ and $16.09^{\circ} \mathrm{C}$ respectively. In the same way, it is observed that the wind speed is relatively constant during spring and summer, while in autumn and winter there are increases that contribute to dissipating heat from the surface of the earth, which in turn leads to low ambient temperatures. Additionally, the average normal beam radiation is relatively higher than other geographic regions with an annual average of $2 \mathrm{~kW} / \mathrm{m}^{2}$. Finally, it is worth mentioning that the relative humidity increases during summer, reaching $70 \%$, which corresponds to the rain season, causing the relatively low ambient temperatures and low solar radiation reported during this same period. In addition, the geographic characteristics of Mexico City are presented in Table 2 based on the information provided by the National Institute of Statistics and Geography through the National Geodesic Network [52]. Finally, for simulation purposes, this study evaluates the performance of the direct-expansion solar-assisted heat pump system throughout the year, divided into four seasons, whose corresponding data is shown in Table 3 . 


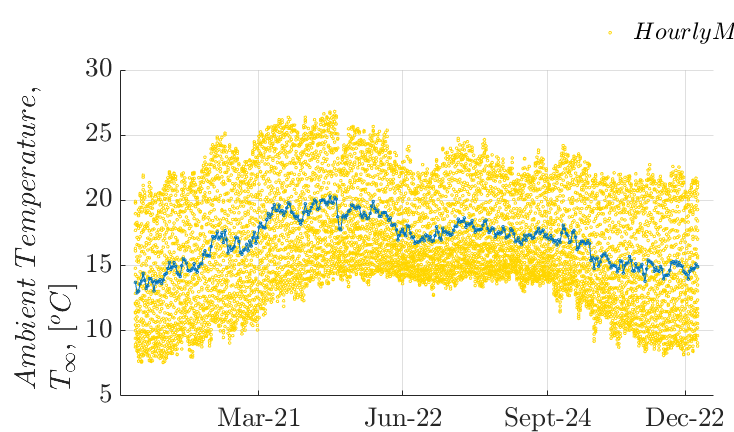

(a)

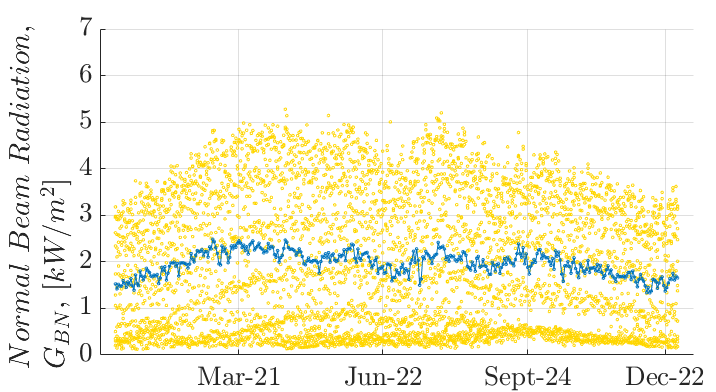

(c)

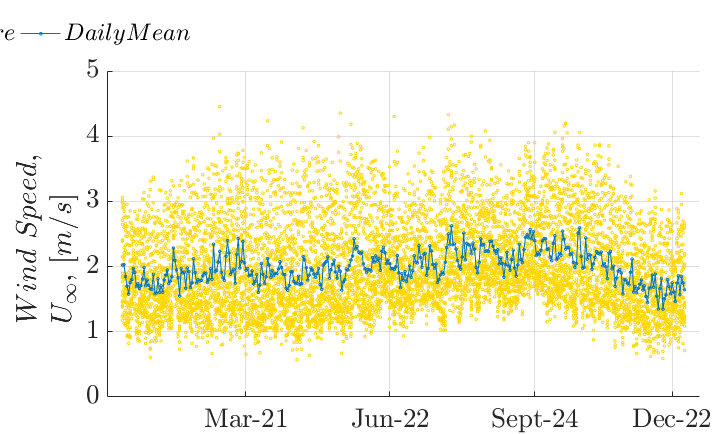

(b)

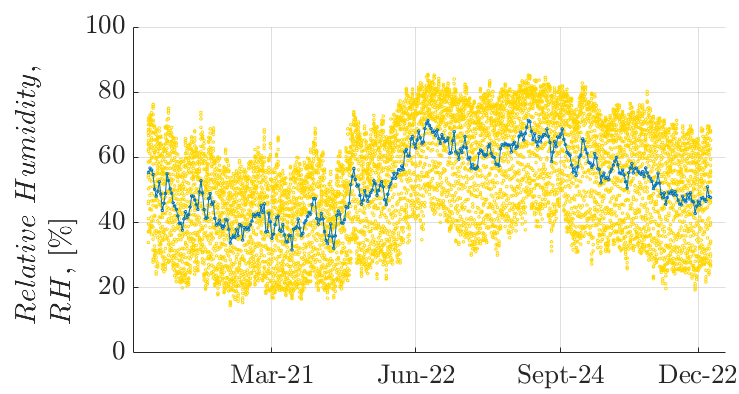

$(d)$

Figure 2. Average atmospheric conditions of Mexico City. (a) Ambient temperature, (b) Wind speed, (c) Normal beam radiation, (d) Relative humidity.

Table 2. Geographic characteristics of Mexico City.

\begin{tabular}{cc}
\hline Geographic Characteristics & Statistics \\
\hline Local latitude & 19.43 decimal degrees \\
Local longitude & -99.13 decimal degrees \\
Standard latitude & 19 decimal degrees \\
Standard longitude & -99 decimal degrees \\
Altitude & $2267.25 \mathrm{~m}$ \\
Atmospheric pressure & $77.99 \mathrm{kPa}$ \\
\hline
\end{tabular}

Table 3. Temporal reference.

\begin{tabular}{cccc}
\hline Season & Standard Calendar & Solar Day & Period \\
\hline Spring & 21 March to 21 June & $80-172$ & 93 days \\
Summer & 22 June to 23 September & $173-266$ & 94 days \\
Autumn & 24 September to 21 December & 267-355 & 89 days \\
Winter & 22 December to 20 March & $356-79$ & 89 days \\
\hline
\end{tabular}

\section{Results and Discussion}

Once the input variables have been defined, the model is used to simulate the performance of the heat pump to corroborate the feasibility of its installation and operation in Mexico City, with the aim of heating $300 \mathrm{~L}$ of water at an outlet temperature of $51^{\circ} \mathrm{C}$. Therefore, the performance of the thermal machine is evaluated in terms of the work time, $\Delta t$, the number of collectors-evaporators, $N_{\text {Evap, }}$ and the working fluid, as functions of the thermal capacity, the COP and the resulting energy exchange of the heat pump system.

\subsection{Thermal Capacity}

As stated in Section 2, the thermal capacity, $\tau_{C}$, Equation (1), establishes the relationship between the capacity that the heat pump has to transfer energy to a determined volume of product and the 
minimum energy demanded by said volume to reach and maintain the desired output conditions. A minimum thermal capacity $\tau_{C}=1$ is desired since it ensures that the heat pump will maintain a satisfactory performance during the determined period of time and under any circumstance or operation scheme, since it indicates that the magnitude of the heat flow absorbed from the environment is greater than that required by the volume of water.

One of the purposes of this model is to establish guidelines concerning the design of applied heat pump cycles, therefore this parameter is considered conditional, since it allows the user, designer or operator, to evaluate the theoretical performance of the heat pump based on the geographic and atmospheric conditions under which the DXSAHP is operating. Based on this, a feasibility study is carried out and the corresponding results are illustrated in Figures 3-6.
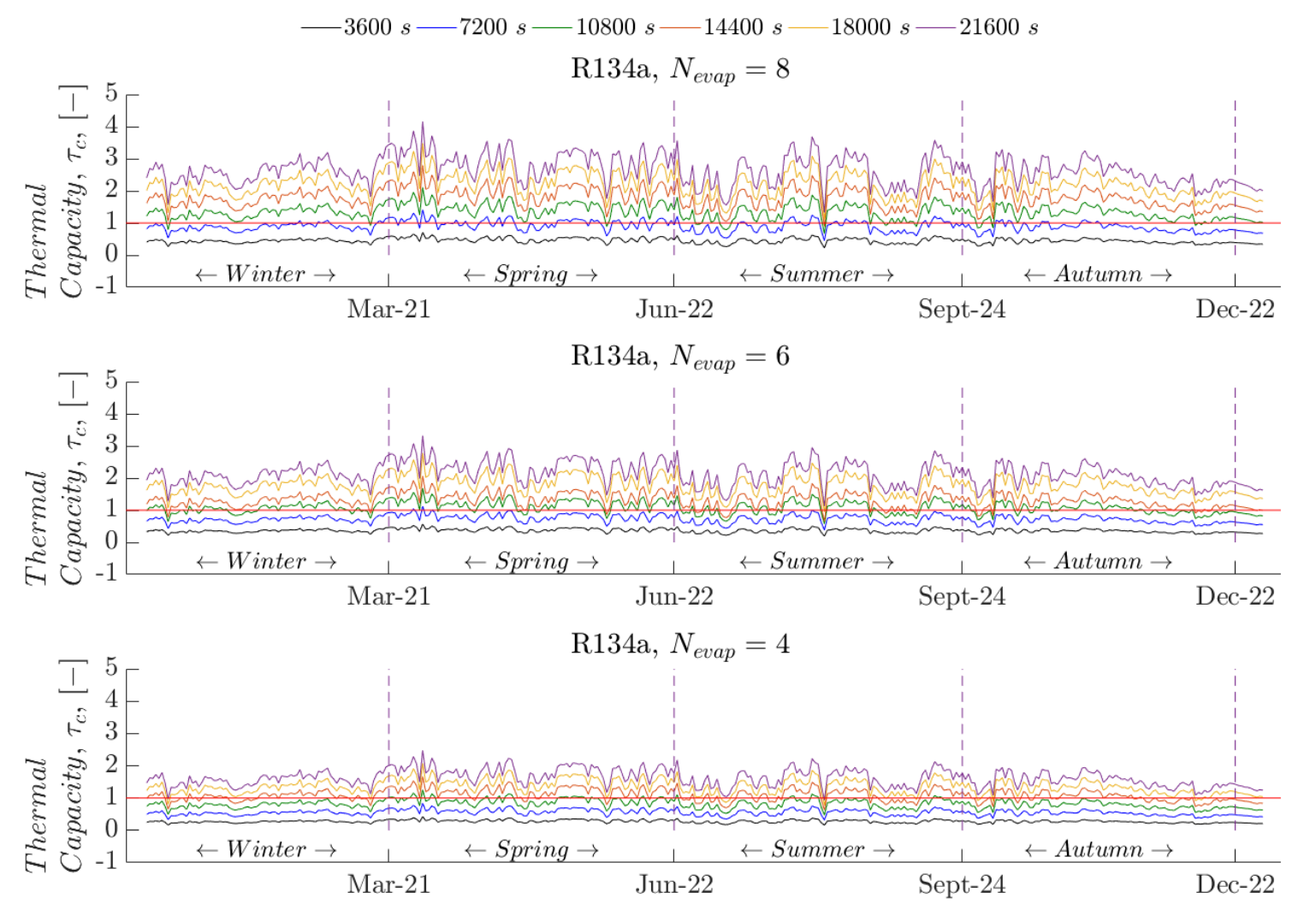

Figure 3. Thermal capacity of the heat pump during the year using R134a as working fluid.

A first observation is that the R134a working fluid presents a global thermal capacity $\overline{\tau_{C}}=1.55$ and when used as a reference, the R410A refrigerant is the fluid that provides the heat pump with the highest thermal capacity, followed by the R407C, R404A, with average increases equivalent to $21.7 \%$, $10.4 \%$ and $4.6 \%$ respectively. It is also seen that spring season presents the best weather conditions, providing the DXSAHP with a seasonal average thermal capacity of 1.73 , followed by summer with 1.52 , autumn with 1.47 and finally winter with 1.25. This minimal variation indicates that Mexico City has relatively advantageous atmospheric conditions allowing the installation of a heat pump with such characteristics.

Furthermore, for the R134a refrigerant, a minimum worktime of $2.5 \mathrm{~h}$ is required when using 8 collectors-evaporators, based on the optimum condition, $\tau_{C}=1$ and when reducing the total heat transfer area, the minimum work time needed to reach the output conditions increases $60 \%$ for 6 panels and $80 \%$ for 4 . This feature also occurs when employing R404A and R407C with comparable increases, while the R410A, due to its heat absorption properties, requires a minimum of $2 \mathrm{~h}$ of operation with 8 collectors-evaporators, $3 \mathrm{~h}$ with 6 collectors and $4 \mathrm{~h}$ with 4 collectors. 

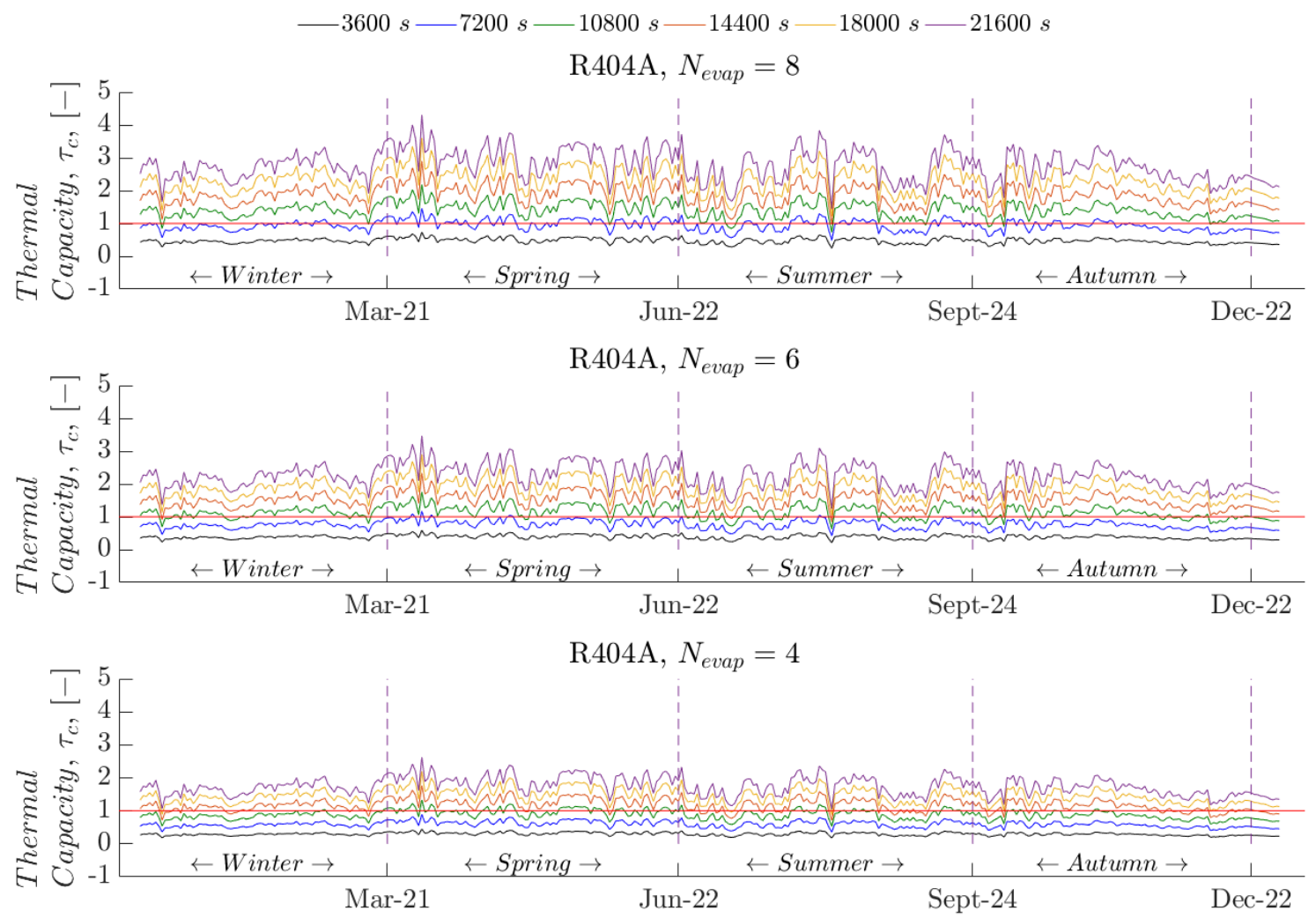

Figure 4. Thermal capacity of the heat pump during the year using R404A as working fluid.
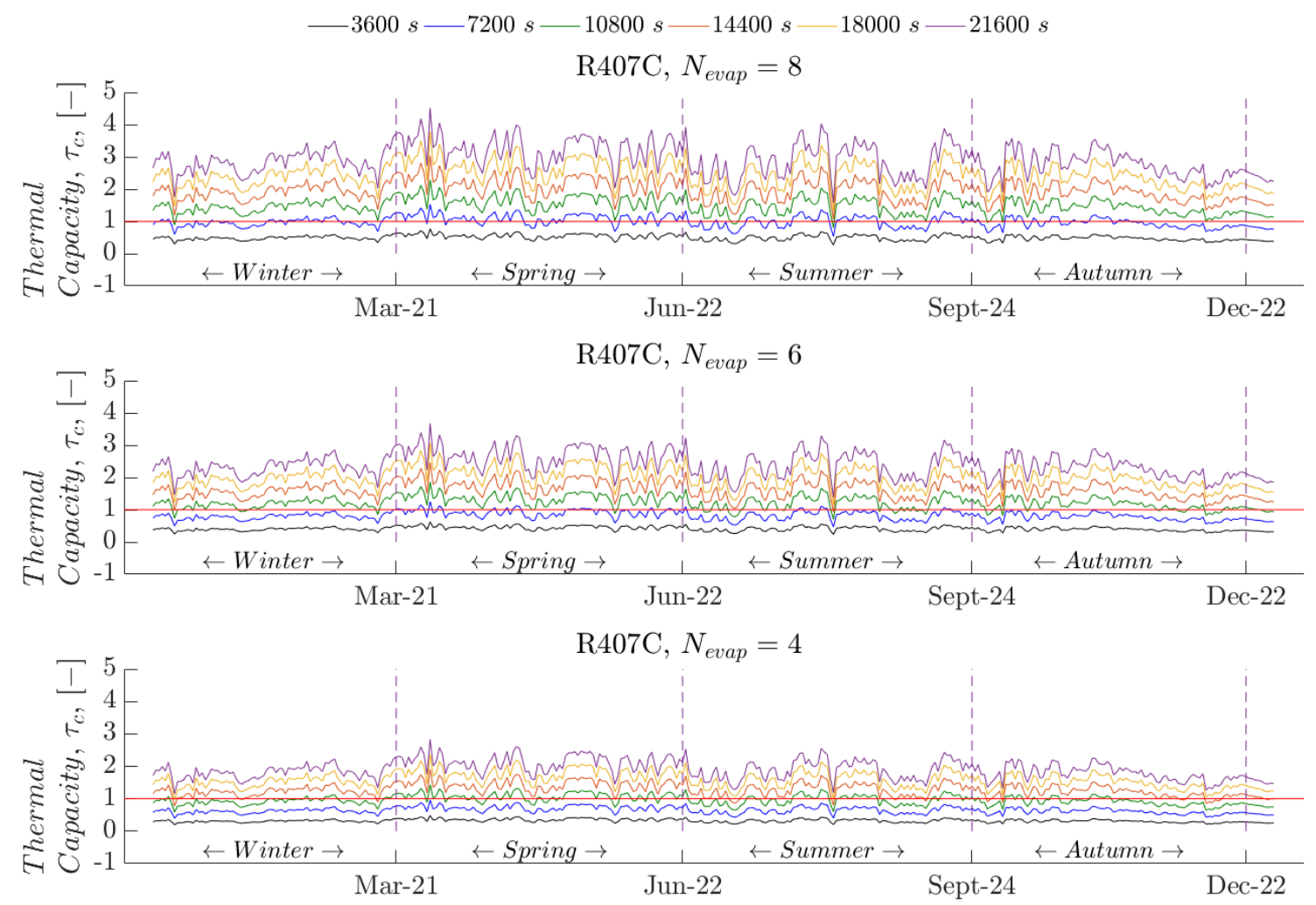

Figure 5. Thermal capacity of the heat pump during the year using R407C as working fluid. 

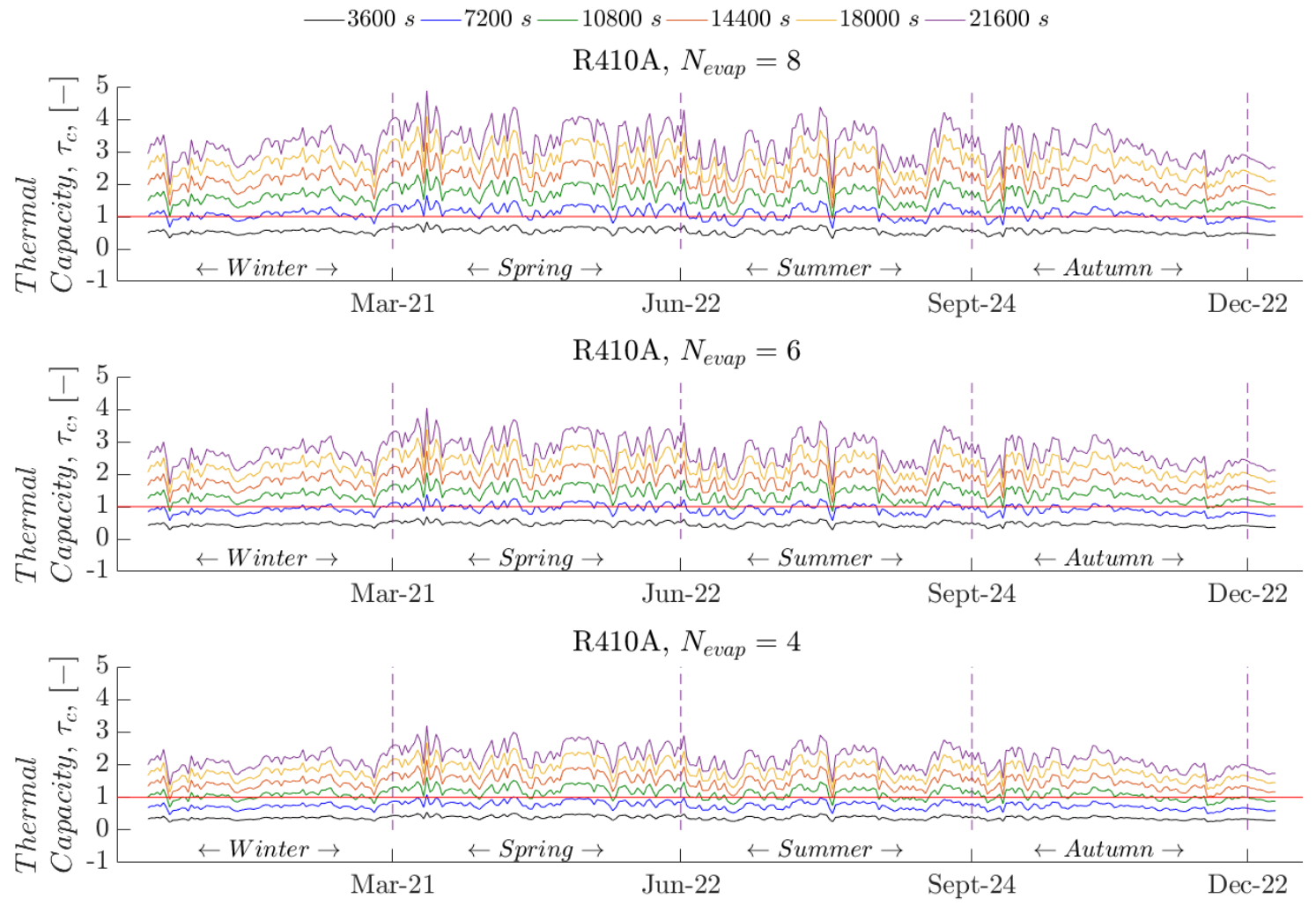

Figure 6. Thermal capacity of the heat pump during the year using R410A as working fluid.

It can be seen that, for all cases, a minimum worktime equivalent to $4-4.5 \mathrm{~h}$ is necessary for the heat pump to reach the desired outlet hot water temperature, while maintaining an acceptable performance.

Moreover, Figure 7 is presented. This illustrates the effect that atmospheric conditions and the number of panels have on the refrigerant performance. The performance of the DXSAHP using 4, 6 and 8 collectors-evaporators is shown and it is observed that during spring the highest thermal capacity is obtained, while in summer, contrary to what was predicted, and because of the rain season, the performance of the heat pump is diminished. This effect can be mitigated through an increase in the total heat transfer area. Moreover, during autumn and winter, due to atmospheric conditions, the thermal capacity is also reduced; however, because of the warm climate and advantageous atmospheric conditions that prevail in the region, even during these seasons, it is possible to operate the DXSAHP as a water heating system. To complement this, Table 4 presents the difference between working fluids in terms of the average annual thermal capacity when operating during $4 \mathrm{~h}$.

Table 4. Average annual thermal capacity during $4 \mathrm{~h}$ of operation.

\begin{tabular}{cccc}
\hline \multirow{2}{*}{ Refrigerant } & \multicolumn{3}{c}{ No. of Collectors-Evaporators } \\
\cline { 2 - 4 } & $\mathbf{8}$ & $\mathbf{6}$ & $\mathbf{4}$ \\
\hline R134a & 1.7812 & 1.3124 & 1.0901 \\
R404A & 1.8635 & 1.5179 & 1.1724 \\
R407C & 1.9658 & 1.6202 & 1.2747 \\
R410A & 2.1675 & 1.8220 & 1.4765 \\
\hline
\end{tabular}



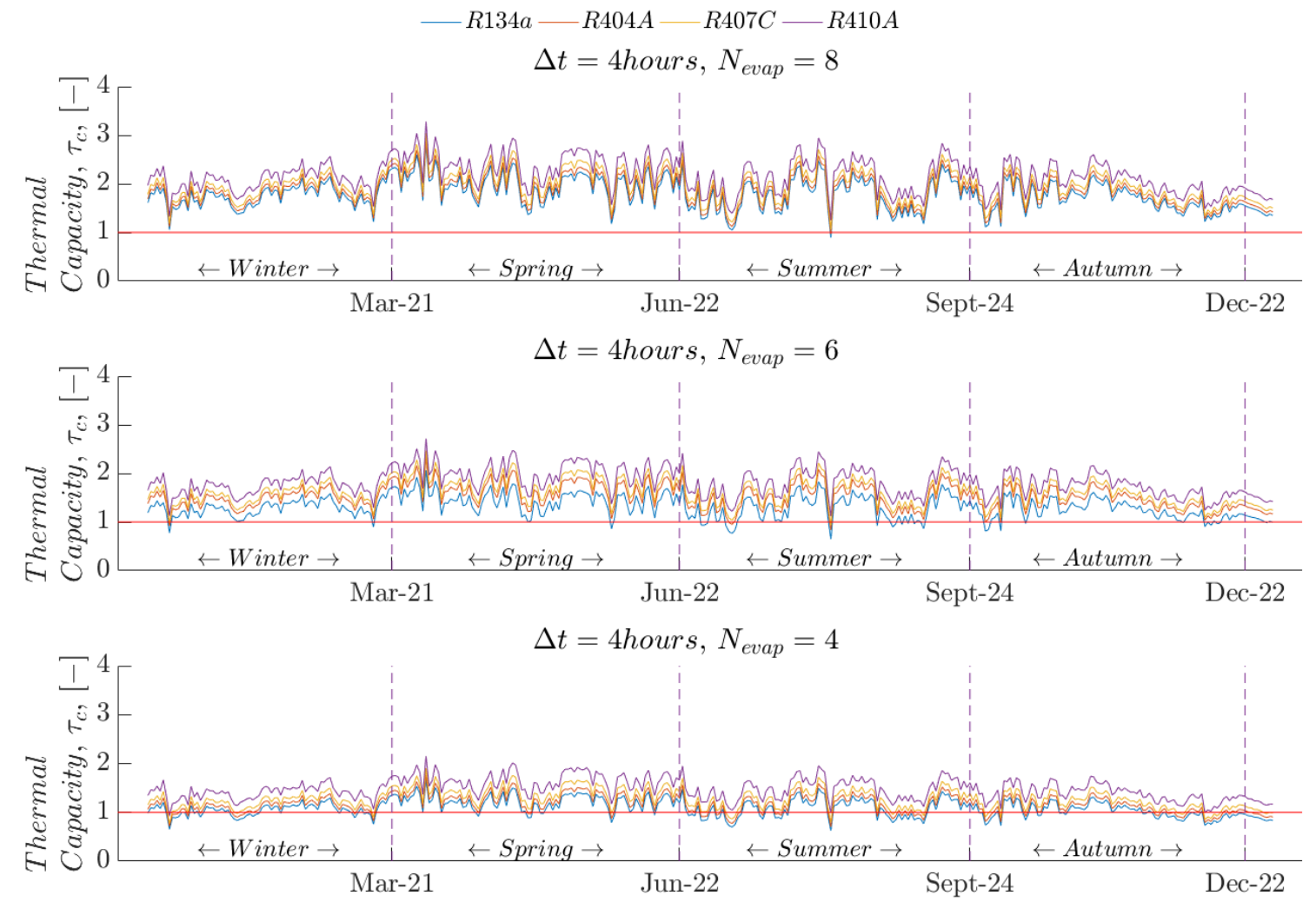

Figure 7. Thermal capacity of the heat pump during the year for all refrigerants, working $4 \mathrm{~h}$.

This variation between refrigerants is relatively small when operating with the upper and lower limits of the heat transfer area, eight and four panels respectively, due to an increment in the effect of the convective phenomenon when the solar collection area is also increased. This increase does intensify the heat absorption of the collectors; nonetheless, this transfer is limited by the heat capacity of the refrigerant. Diversely, when reducing the heat transfer area, the solar radiation incident on the collectors is considerably decreased and, despite the refrigerant heat capacity, total heat absorption is lessened. This balance implies that, in terms of design, the selection of the working fluid is related to the magnitude of the solar collection area.

Figures 8-10 illustrate some specific features of an intrinsic advantage of the thermal capacity. In addition to quantifying the magnitude of the performance of the heat pump in terms of a relative efficiency, the density distribution of the thermal capacity also provides categorical data based on the percentage of samples reaching, or not, the desired output conditions under a given operation scheme. These figures highlight that, for all the heat transfer areas studied, the data reported during winter and summer are concentrated in a certain region, while in spring and autumn, a wider dispersion of the same data is observed, due to slightly higher variations of the atmospheric conditions.

In addition, it is seen that throughout the year, the heat pump maintains a relatively high condensation heat flow, $\dot{Q}_{C}$, within a range of 4 to $8 \mathrm{~kW}$, which implies that the atmospheric conditions of Mexico City are particularly advantageous. On the other hand, the thermal load required, $\dot{q}_{T}$, varies between seasons, within a $2.5-3.5 \mathrm{~kW}$ range, where the lower bounds are obtained during spring and summer. 

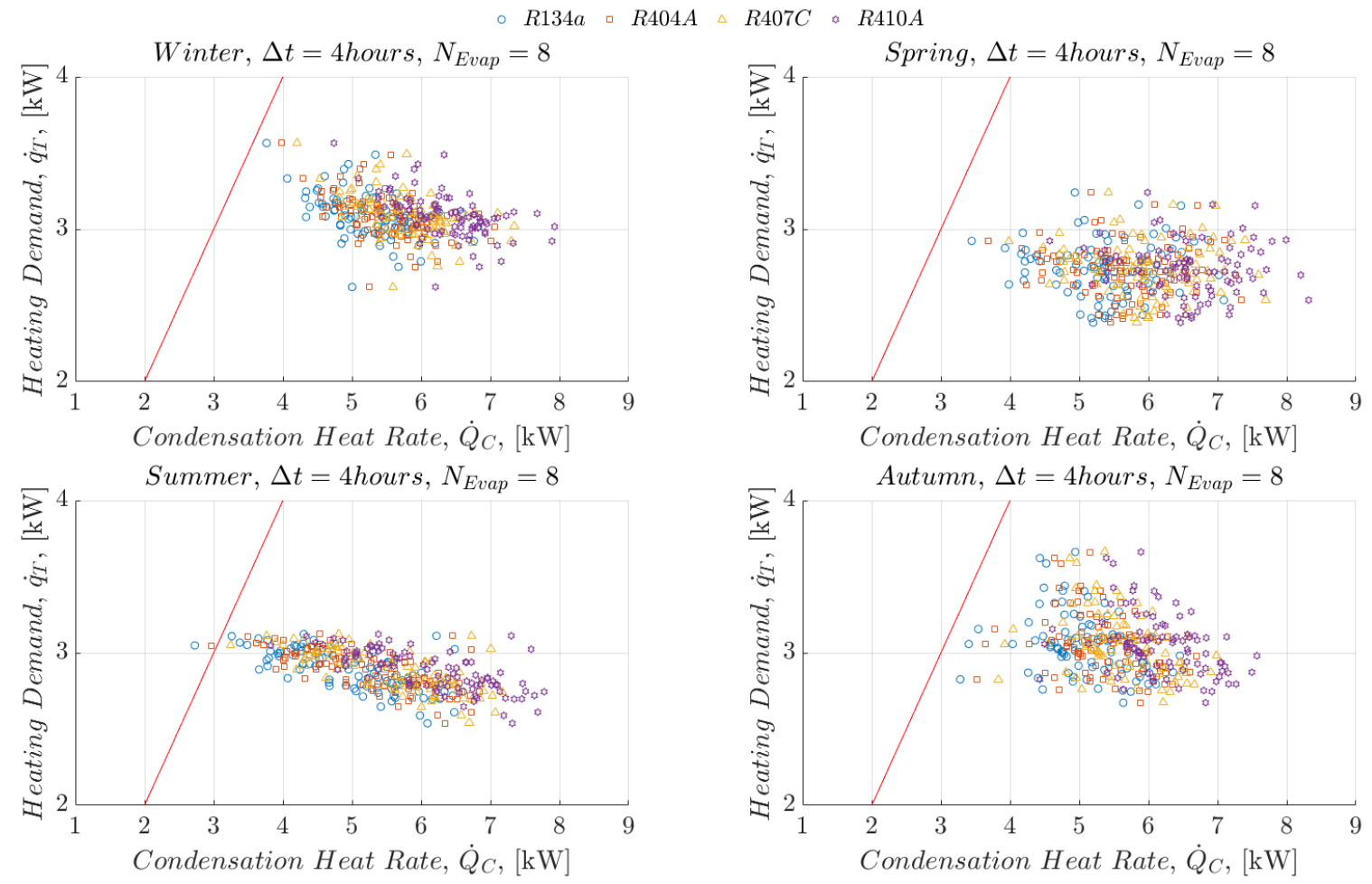

Figure 8. Thermal capacity seasonal density rate for all refrigerants and eight collectors during $4 \mathrm{~h}$.
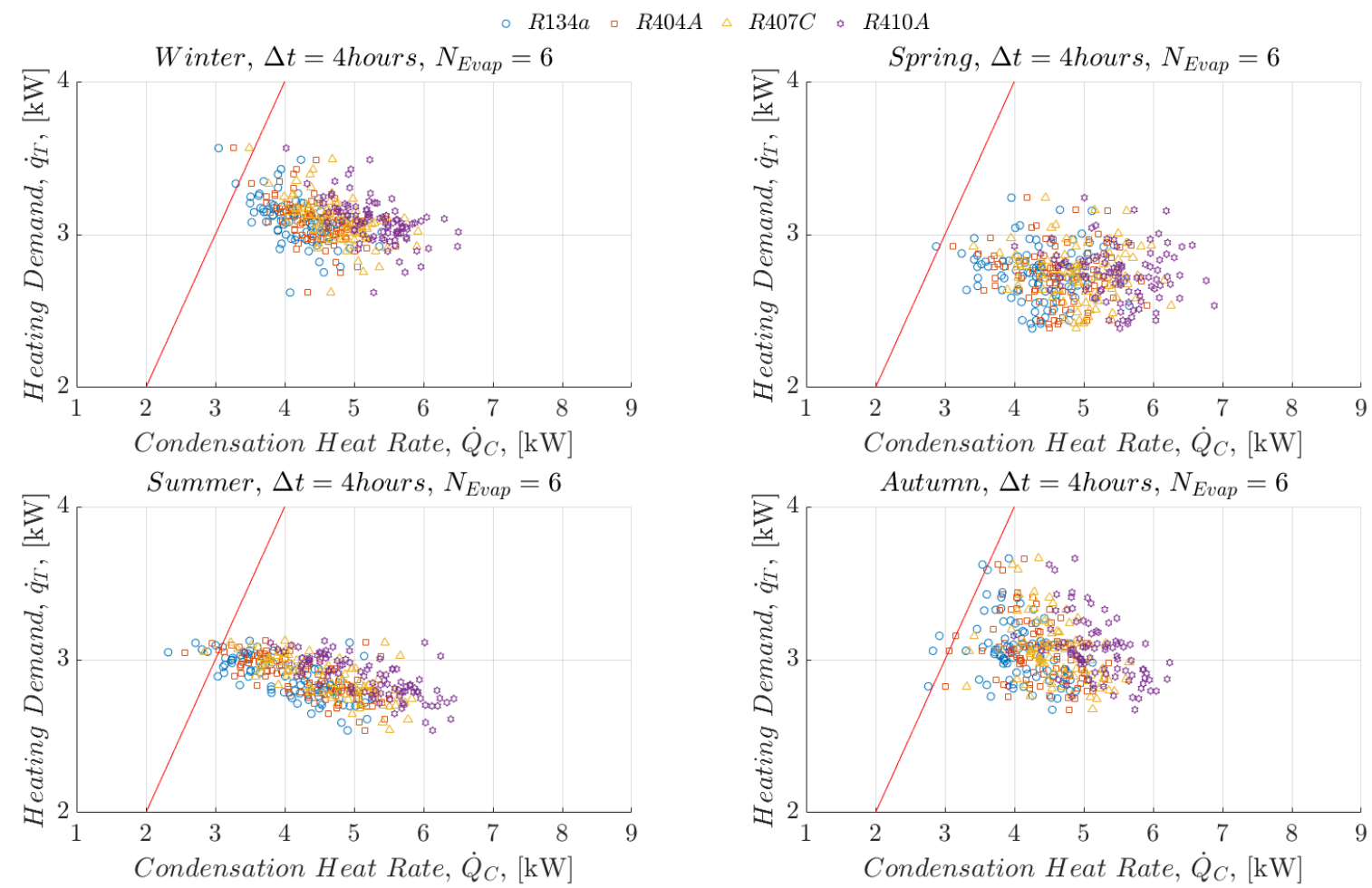

Figure 9. Thermal capacity seasonal density rate for all refrigerants and six collectors during $4 \mathrm{~h}$. 

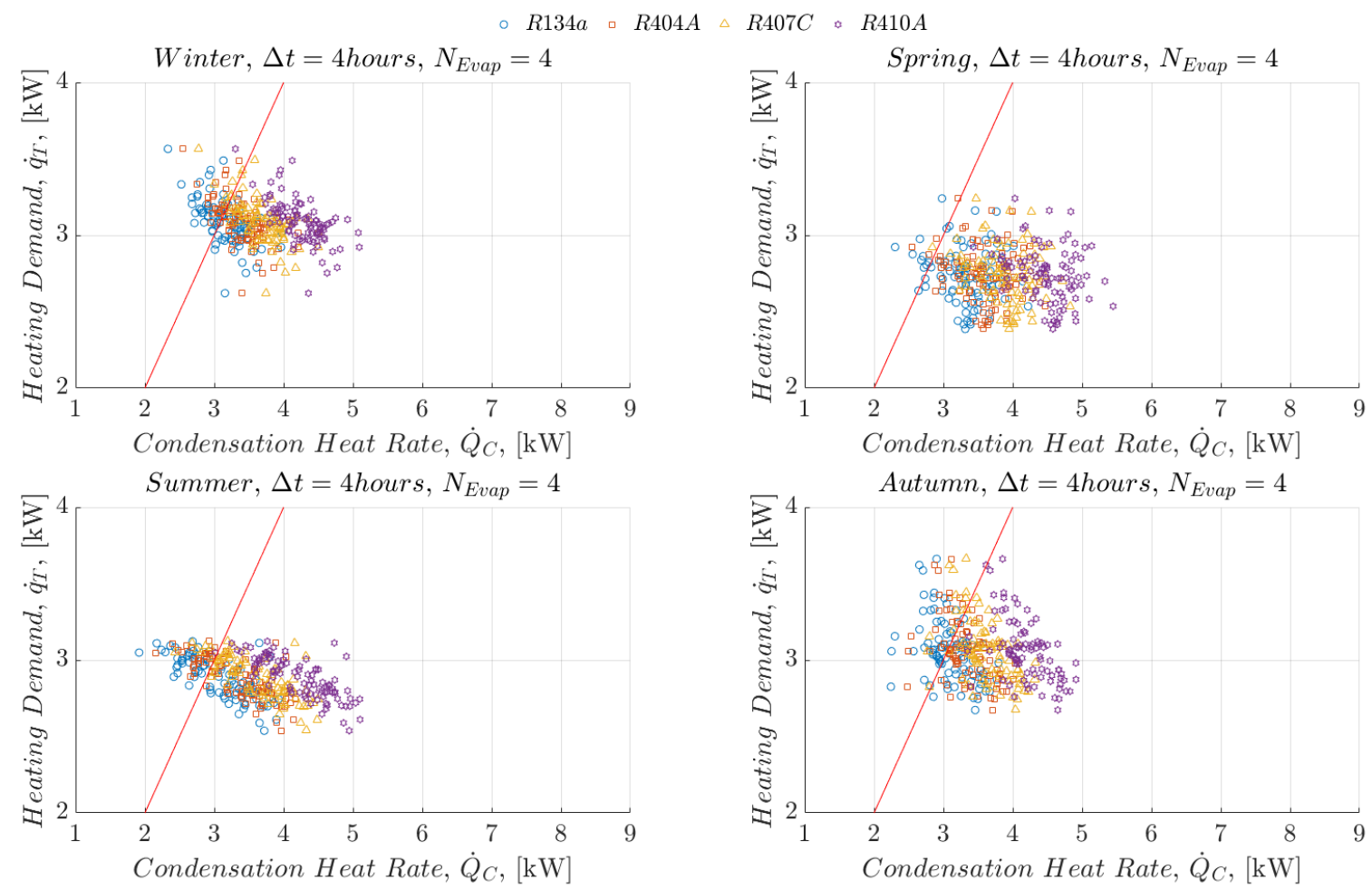

Figure 10. Thermal capacity seasonal density rate for all refrigerants and four collectors during $4 \mathrm{~h}$.

The latter corroborates that the highest and lowest thermal capacity, $\tau_{C}$, occurs during spring and winter respectively, given that it is when atmospheric conditions exert a greater effect on the thermal load required, $\dot{q}_{T}$. This behavior indicates that, for this particular study, relatively neutral atmospheric conditions are preferable; otherwise, the heat absorption and transfer capabilities of the heat pump are severely diminished. An example of this trend occurs during summer, when, despite a high ambient temperature, normal beam radiations are low due to the rain season, therefore, the thermal capacity, $\tau_{C}$, is reduced, which again denotes the benefits provided by solar radiation to the performance of this heat pump setup. Nonetheless, it is convenient to carry out simulations in regions with more extreme weathers, to evaluate the effect that these variations and its combinations may have on the overall operation of the heat pump.

In terms of the heat transfer area, during $4 \mathrm{~h}$ of operation, Figure 8 shows that with eight collectors-evaporators, refrigerants R134a and R404A meet the thermal demand $99.8 \%$ of the year, equivalent to 364 days, while the remaining day, where the thermal demand was not met, taking place in summer. Meanwhile, the R407C and R410A refrigerants comply with $100 \%$ of the tests.

From Figure 9, when employing six panels, R134a complies with $96.7 \%$ of the tests, with 12 days below the minimum and $41 \%$ of the incidents occurring during summer, which is again the season with the highest number of days below the demand requirements. R404A fulfil requirements $99.8 \%$ of the year, with a winter day not satisfying the thermal demand, while fluids R407C and R410A once again met the thermal load required for all tests.

Finally, Figure 10 shows the evaluation for four evaporation plates showing that R134a complies for $83 \%$ of the tests, with 62 days of energy demand non-compliance, among which $40 \%$ occur during summer. R404A complies for $94.5 \%$ of the days and $45 \%$ of the 20 remaining days during fall. R407C obtains a $97.8 \%$ performance level, with eight unsatisfactory days remaining (two in winter, three in autumn and three in summer). Finally, R410A has $100 \%$ of tests satisfying the thermal demand during the year. 


\subsection{Heating Demand}

From the information obtained in the previous section, it is possible to reduce the volume of product to be heated, in order to increase the thermal capacity of the DXSAHP and Figure 11 is obtained.

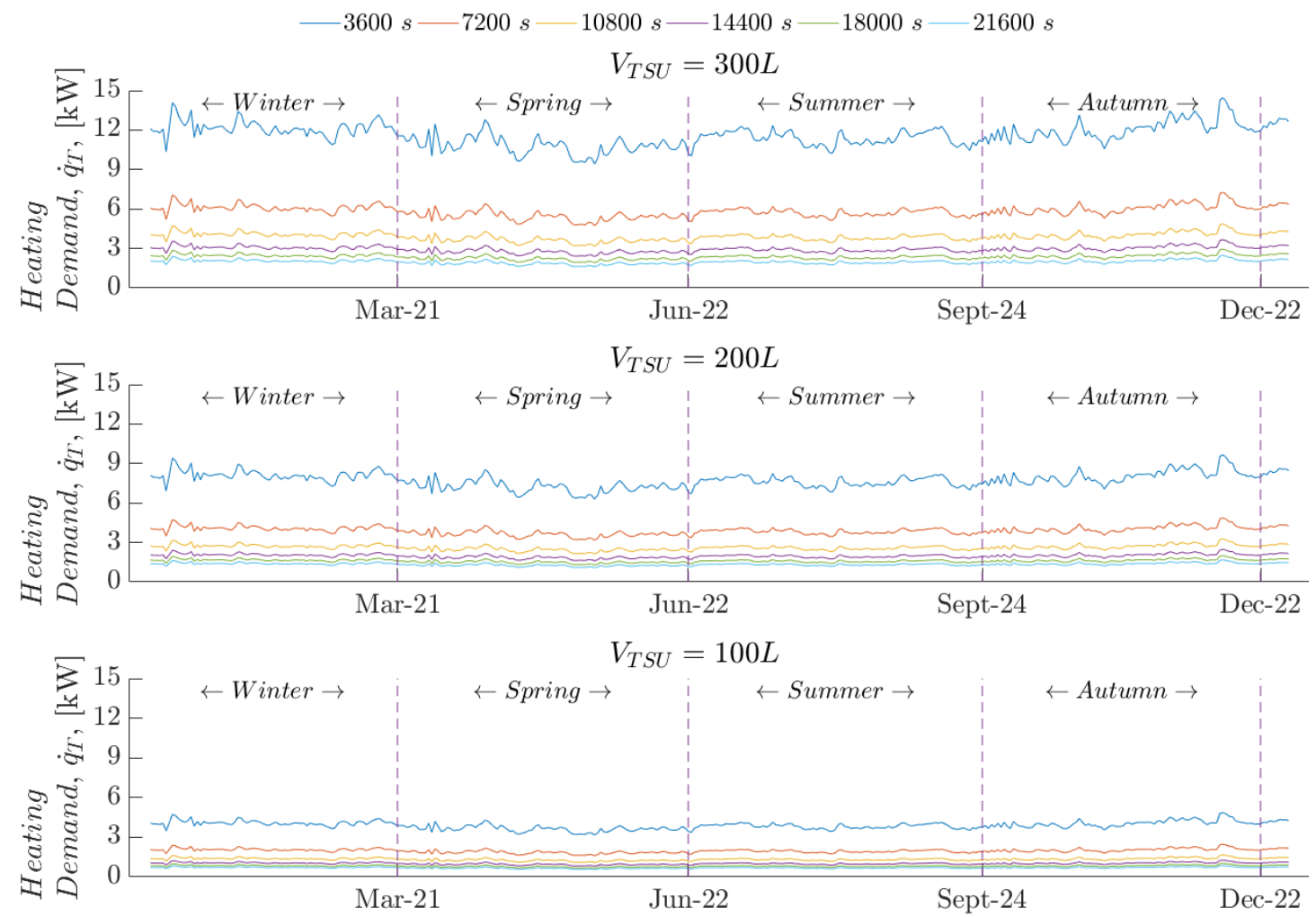

Figure 11. Energy demand throughout the year for all water loads.

It is seen that the energy demand is directly proportional to the water load contained in the thermal storage unit and inversely proportional to the work time. In particular, when heating $300 \mathrm{~L}$ of water, there is an average required thermal load, $\overline{\dot{q}_{T}}$, equal to $4.77 \mathrm{~kW}$, while for $200 \mathrm{~L}$ it is equivalent to $3.20 \mathrm{~kW}$ and for $100 \mathrm{~L}$, it corresponds to an average energy demand of $1.62 \mathrm{~kW}$.

Furthermore, it is seen that the highest thermal load is generated during the first hour of work and, as time passes, due to the energy contribution of the DXSAHP, this demand is reduced by $50 \%$ towards the second hour, $32 \%$ for the third, $24 \%$ for the fourth, $19 \%$ for the fifth and $16 \%$ for the sixth. Finally, the variation of the thermal load, fluctuates as a function of the season; being slightly higher in autumn and winter due to the relatively low cold water inlet temperature, with overall seasonal averages of 2.05 and $2.06 \mathrm{~kW}$ respectively, while overall average values of $1.93 \mathrm{~kW}$ and $1.84 \mathrm{~kW}$ are observed during summer and spring. These magnitudes reveal that even though, the atmospheric conditions, corresponding to each of the seasons, do cause a variation in the heating demand, this variation is relatively minimal, thus making Mexico City a particularly advantageous location for the installation and operation of these appliances; given a steady and low-moderate thermal demand, suitable for this HP configuration.

\subsection{Energy Exchange and Coefficient of Performance}

In order to evaluate the performance of different refrigerants as a function of the thermodynamic cycle, Figures 12 and 13 present the magnitude of the power required by the compressor, $\dot{W}_{C}$, and the condensation heat flow, $\dot{Q}_{C}$, respectively. 


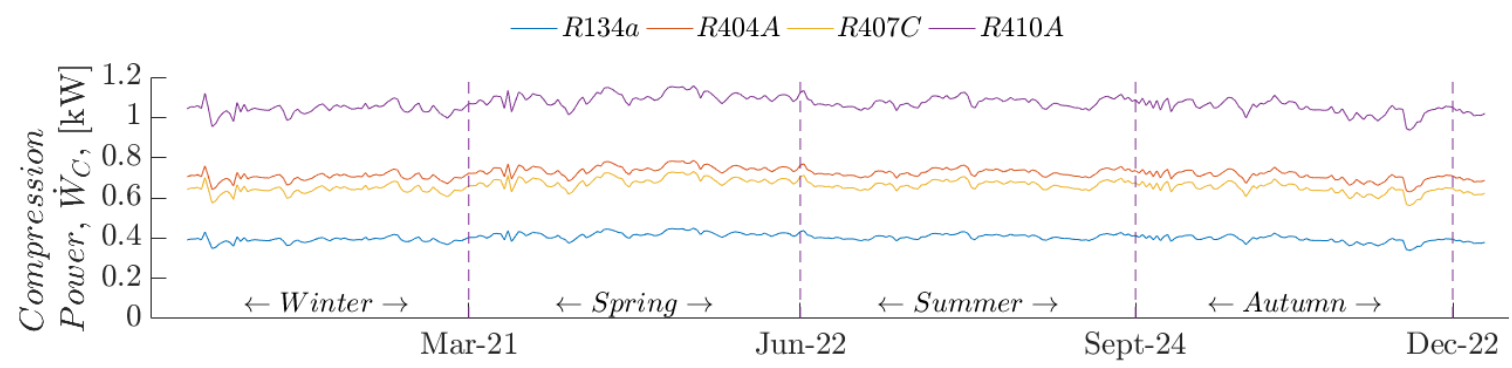

Figure 12. Compression power input for all working fluids throughout the year for all refrigerants.

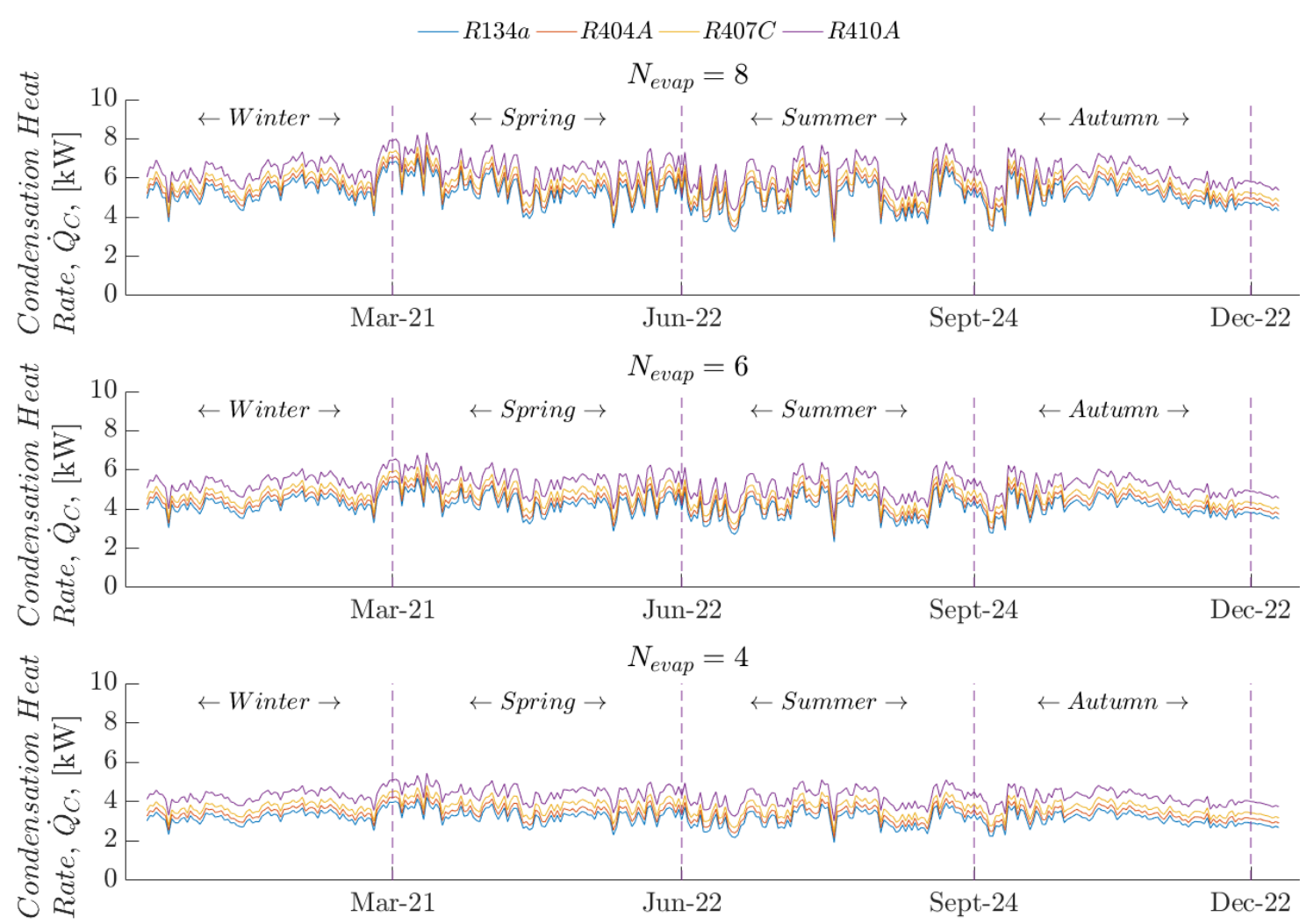

Figure 13. Condensation heat flow throughout the year for all refrigerants using 4,6 and 8 flat-plate solar collectors.

In Figure 12 a first observation is that the compression power input, $\dot{W}_{C}$, is higher when using R410A as a working fluid, equivalent to $1.06 \mathrm{~kW}$. This represents an increase equal to 2.65 times the work required by R134a, followed by the R404A, 1.8 times higher, and finally the R407C with an increase of compression work, 1.6 times more than the R134a. Additionally, the season does not affect considerably the magnitude of the required power, with an average difference between them that ranges between $2 \%$ and $4.5 \%$.

Figure 13 shows that the highest condensation heat flow $\dot{Q}_{C}$ is obtained when employing the combination of 8 flat-plate solar collectors and R410A refrigerant, reaching an annual average equal to $6.31 \mathrm{~kW}$, followed by R407C with $5.72 \mathrm{~kW}$, R404A with $5.42 \mathrm{~kW}$ and finally the R134a with $5.18 \mathrm{~kW}$.

Decrements of 1 and $1.35 \mathrm{~kW}$ are obtained when using six and four evaporation plates, respectively. These magnitudes reveal that this particular setup yields a heat rate between 1.8 and 1.5 refrigeration tons, RT, depending on the working fluid employed. Furthermore, during spring, the maximum global heat flow is achieved, with an average of $5.41 \mathrm{~kW}$, followed by summer with a decrease of $7 \%$, autumn $5 \%$ lower and winter with a $10 \%$ decrease. 
From the energy exchange, it is possible to determine the coefficient of performance of the heat pump cycle, in order to select the working fluid that delivers the best overall performance of the DXSAHP. Figure 14 is the product of this evaluation and, regardless of the magnitude of the condensation heat flow, refrigerant R134a has the highest average coefficient of performance, $\overline{\mathrm{COP}}$, when using eight, six and four evaporation panels due to lower compression power input requirements, the $\overline{\mathrm{COP}}$ values obtained are 12.90, 10.39 and 7.89, respectively. On the other hand, because it requires approximately 2.5 times more compression work, the R410A $\overline{\mathrm{COP}}$ is reduced to 5.92 with eight collectors, 4.97 with six plates and 4.09 when using only four. Moreover, refrigerants R404A and R407C deliver a relatively similar performance; the latter generating a $\overline{\mathrm{COP}}$ slightly higher with 8.69, 7.16 and 5.63, compared to $7.53,6.13$ and 4.73 for R404A.

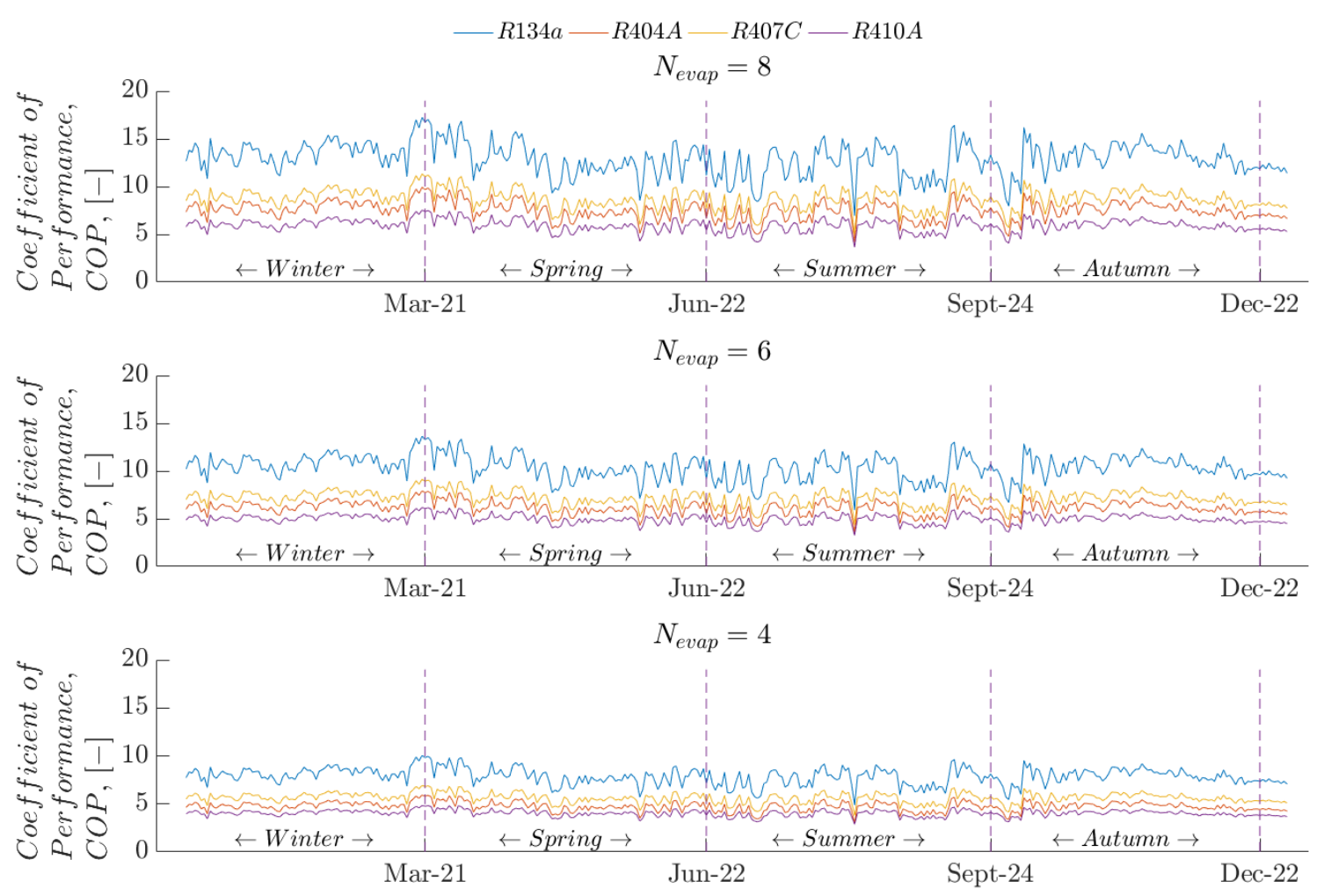

Figure 14. Coefficient of performance throughout the year for all refrigerants and for 4, 6 and 8 flat-plate solar collectors.

Finally, the computed average $\overline{\mathrm{COP}}$ of the DXSAHP for all refrigerants and all areas of solar collection is 4 , with increases of $23 \%$ in spring, $14 \%$ in summer, $15 \%$ in autumn and $17 \%$ in winter.

\subsection{DXSAHP as a Function of the Relative Efficiencies}

Finally, in order to select the refrigerant and the number of collectors-evaporators suitable to obtain the desired output conditions, while maintaining an acceptable performance, it is necessary to evaluate the existent connection between the coefficient of performance, $C O P$, and the thermal capacity of the heat pump, $\tau_{C}$.

With this objective in mind, an inferential statistical analysis is employed, particularly an interpolation method known as estimation of the probability density function, PDE, to deduce the underlying properties of the population, in order to identify the concentration areas of the datasets [53-57].

As a result of the implementation of this statistical method, Figures 15-17 show the tendency of the relative efficiencies of the system in terms of the probability function, where the zone of maximum concentration is highlighted as well as the samples considered as outliers or isolated events. 

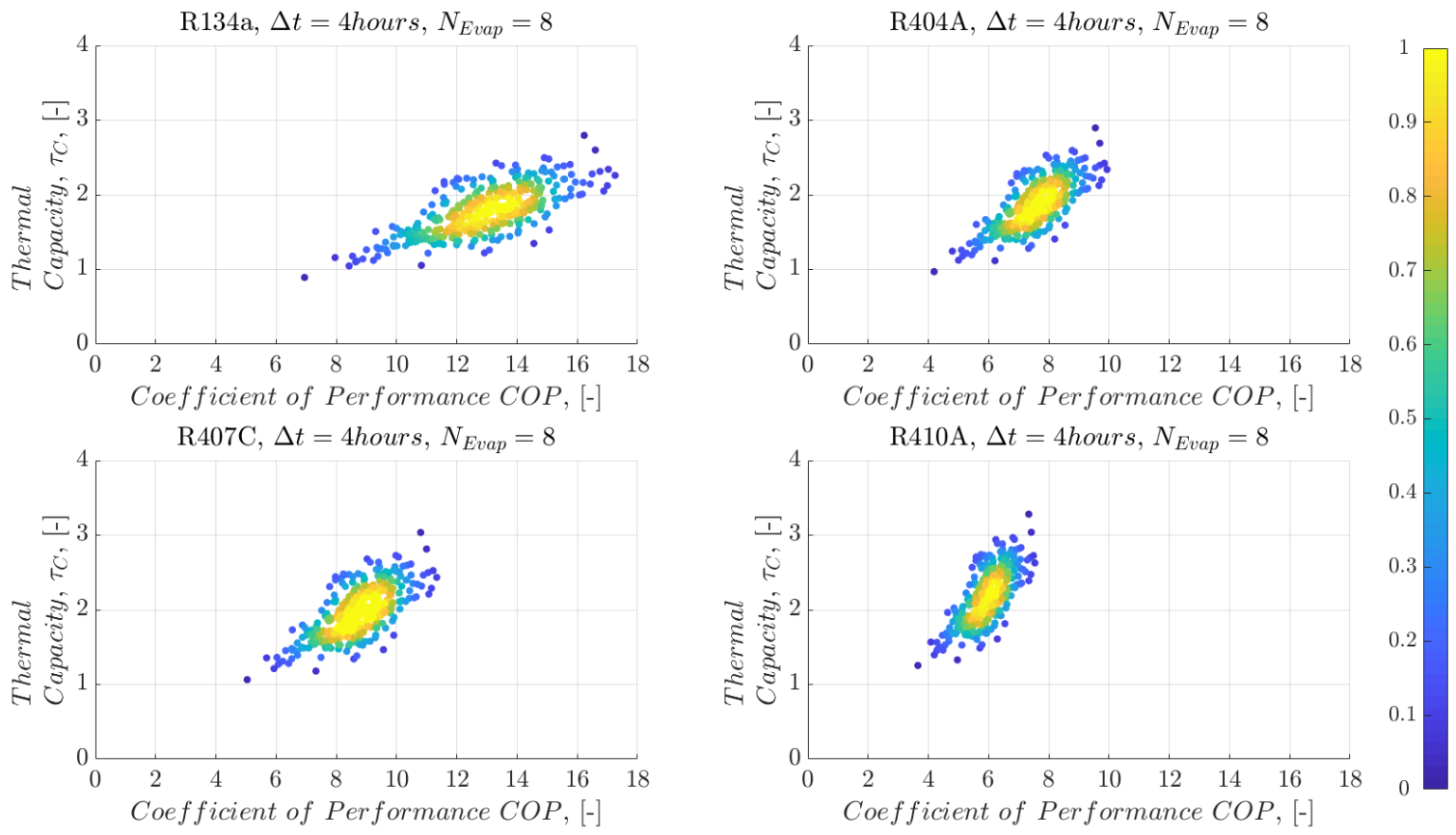

Figure 15. Probability density estimation of the relative efficiencies for all refrigerants and eight collectors.
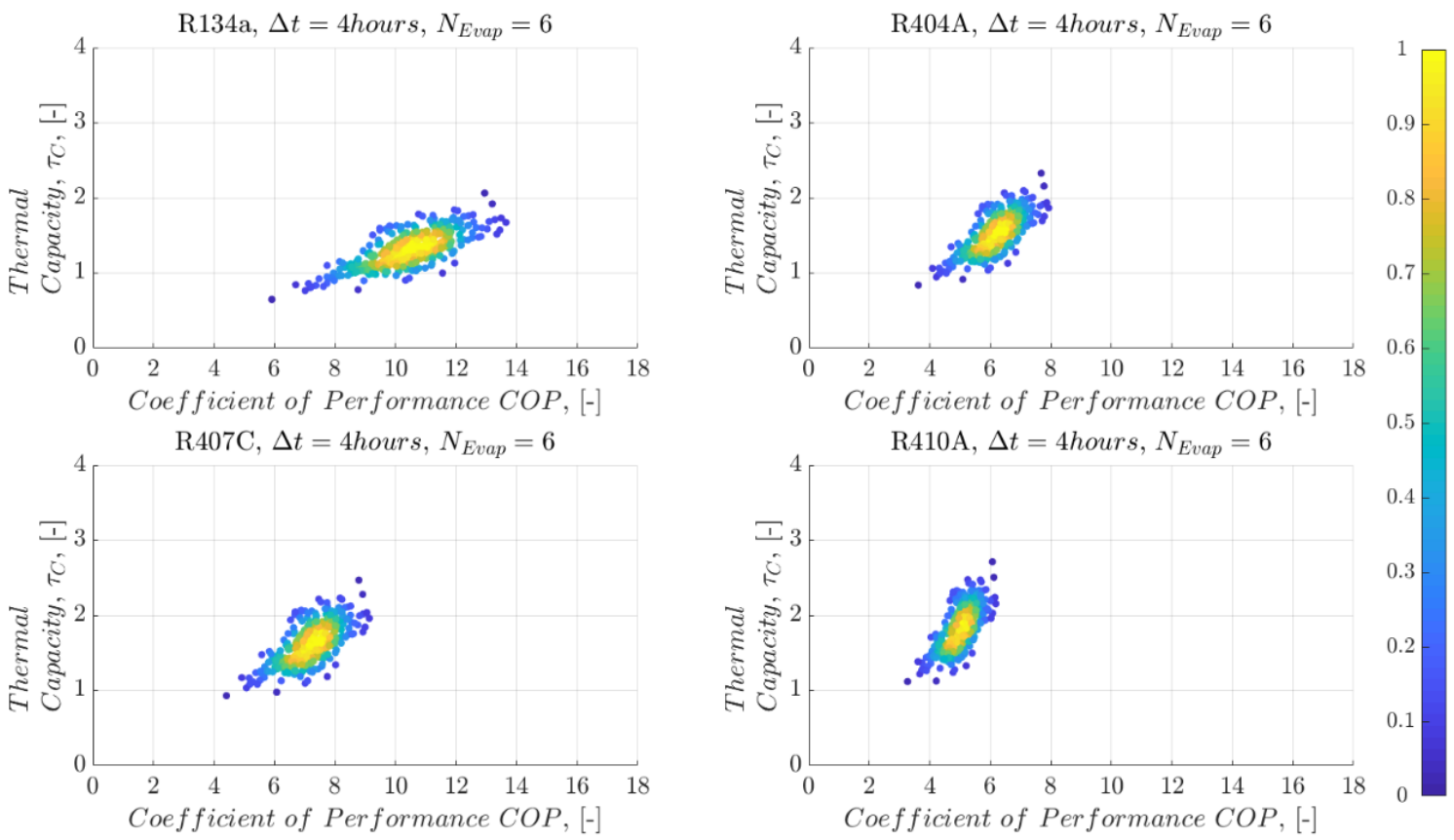

Figure 16. Probability density estimation of the relative efficiencies for all refrigerants and six collectors. 

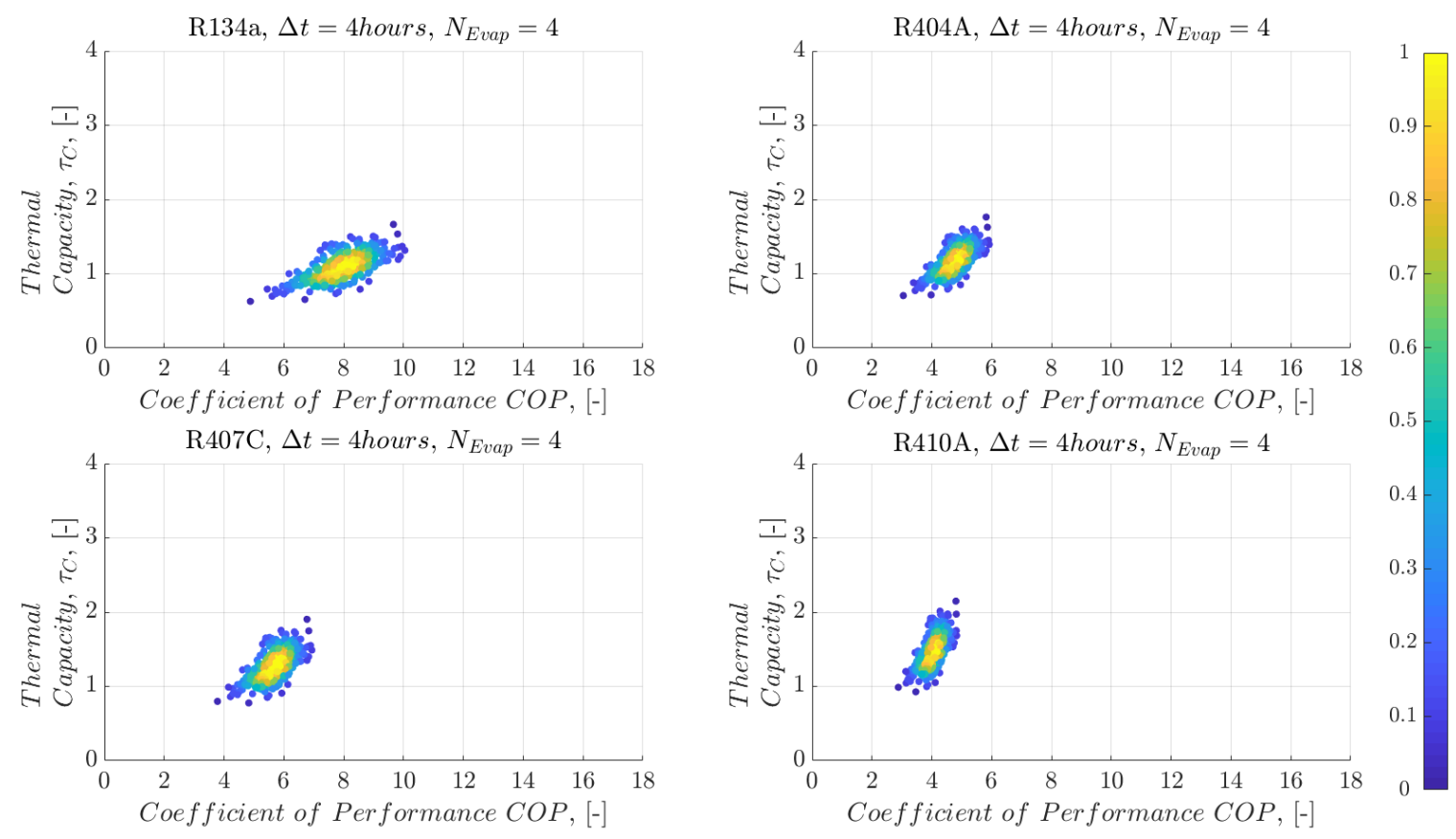

Figure 17. Probability density estimation of the relative efficiencies for all refrigerants and four collectors.

The purpose of these figures is to combine the information provided by both relative efficiencies in order to provide guidelines for the design of a device able to achieve a suitable performance based on both the atmospheric and operation conditions.

Based on a qualitative analysis of these figures, R134a proves to be the refrigerant that has a more dispersed dataset, while the rest remain relatively concentrated in a specific region, indicating that R134a is a working fluid considerably more susceptible to changes in both atmospheric conditions and design parameters, exerting a significant effect on the performance of the heat pump.

Furthermore, for all refrigerants, this dispersion increases when employing a larger heat transfer area, due to an increase in the magnitudes of the energy exchanges, $\dot{Q}_{E}, \dot{Q}_{C}$, and $\dot{W}_{C}$, of the heat pump, which expands the ranges of both the thermal capacity and the performance coefficient.

In the same figures, it can observed that the R134a working fluid is the refrigerant that provides the DXSAHP with the highest COP, but also with the lowest thermal capacity, contrary to R410A, which presents an opposite behaviour due to its heat transfer properties. Meanwhile, the remaining working fluids, R404A and R407C, show more consistent patterns, with moderate fluctuations compared to the other refrigerants and with similar behaviours between them, both maintaining acceptable $\tau_{C}$ levels and a relatively high $C O P$, with the latter delivering a slightly better performance.

For this specific study, given the advantageous weather conditions that prevail in Mexico City, acceptable COP levels are reached for all refrigerants and all solar collection areas [58] as seen in Table 5. Nonetheless, it was found that ultimately, the design of the DXSAHP system, particularly the refrigerant selection, was rather influenced by the number of collectors, through external factors such as space availability and/or installation costs. With 8 collectors, all working fluids perform above the limits imposed by the thermal capacity. However, R134a is the one that provides the heat pump with the highest $C O P$, nonetheless, when 4 collectors are installed, R410A becomes the most viable choice, forgoing a relatively higher $C O P$ in favor of reduced installation costs. 
Table 5. Tendency ranges of the relative efficiencies of the DXSAHP system.

\begin{tabular}{|c|c|c|c|c|c|c|}
\hline \multirow{3}{*}{ Refrigerant } & \multicolumn{6}{|c|}{ No. of Collectors } \\
\hline & \multicolumn{2}{|c|}{8} & \multicolumn{2}{|c|}{6} & \multicolumn{2}{|c|}{4} \\
\hline & $\tau_{C}$ & COP & $\tau_{C}$ & COP & $\tau_{C}$ & COP \\
\hline R134a & $1.5-2$ & $12-14$ & $1-1.5$ & $9.5-11$ & $0.9-1.3$ & $7-9$ \\
\hline R404A & $1.5-2.2$ & $6.5-8.5$ & $1.3-1.8$ & $5.5-7$ & $1-1.4$ & $4-5$ \\
\hline R407C & $1.6-2.3$ & $8-10$ & $1.4-1.9$ & $6.5-8$ & $1-1.5$ & $5-6$ \\
\hline R410A & $1.8-2.5$ & $5.5-6.5$ & $1.5-2.1$ & $4.5-5.5$ & $1.3-1.7$ & $3.5-4.5$ \\
\hline
\end{tabular}

\subsection{Optimization Implementation}

The study now focuses on those particular configurations characterized by an optimal thermal capacity, $\tau_{C}$ Recalling that, $\tau_{C}$ represents the relationship between the capacity of the heat pump to transfer energy to a determined volume and the energy demand required to reach and maintain the desired output conditions, see Equation (16), a thermal capacity $\tau_{C}=1$ is desired, since this value means an optimal balance between energy requirements and utilization.

Therefore, the design and operation parameters must be tuned in such way that the corresponding thermal capacity is equal to 1 . The previous statement may be re-formulated as an optimization problem consisting in determining the operation conditions that minimize the quadratic difference $O^{2}=\left(\tau_{C}-1\right)^{2}$. Obviously, $O^{2}=0$ implies $\tau_{C}=1$. In this framework, the design and operation parameters represent the decision variables and include the working fluid choice, the worktime and the number of collectors to be installed, i.e. the heat transfer area. In order to manipulate only numerical variables, the working fluid was considered as a parameter and actually four different optimization problems were solved, one for each of the refrigerants. The resulting optimization problem can be formulated as in Equation (17), for each working fluid:

$$
\min _{\Delta t, A_{\text {Evap }}} O^{2}=\left(\tau_{C}-1\right)^{2}
$$

Although the problem described in Equation (2) is expressed as an unconstrained optimization problem, it should be recalled that the constraints are implicitly embedded in the simulator developed in EES. Consequently, there is no mathematical model at hand that could potentially be solved by an exact solution algorithm. Thus, the use of a metaheuristic optimization method looks rather adapted for solving this problem, due to their trial-and-error based working mode that does not need any favourable characteristics of the objective function and constraints (mainly, continuity, derivability, convexity). On the other hand, it must be mentioned that metaheuristics can ensure neither the optimality nor even sub-optimality, making it impossible to evaluate the final quality of the solutions found. This is why the use of this kind of techniques typically involves repeatability studies requiring several executions of the solution algorithm.

In this study, the used simulator, EES, has embedded a specific implementation of a Genetic Algorithm (GA) [59] which was employed to conduct the optimization; the consequent post-processing of the data was carried out using MATLAB.

Genetic Algorithms are a well-known optimization technique that belongs to the Evolutionary Algorithms class, whose main feature is a population of solutions maintained and evolved during a certain number of generations (iterations of the algorithm) [60-62].

Designed as an imitation of the evolutionary processes observed in nature, variation operators based on both inheritance and stochastic concepts are applied to produce new individuals, or solutions to the considered optimization problem. The offspring pool is evaluated in order to assign a fitness that generally represents the quality of the solution in terms of the objective function (for a minimization problem, a high fitness means a low objective function). Then, "natural" selection, also implemented in a probabilistic manner for both parent and survivor selection, is a tool that directs the search 
towards promising regions of the decision space, with high fitness values. The evolutionary process is iterated for a defined number of generations, during which the frequency of "good genes", i.e. those that allow reaching low objective values, increases among the population, leading to a final set of "adapted" individuals.

The particular implementation used here [59] employs canonical operators such as binary encoding, proportional selection, k-point crossover and bit swap mutation. The operation parameters of the GA are shown in Table 6.

Table 6. Working parameters of the genetic algorithm.

\begin{tabular}{cc}
\hline No. of Individuals & $\mathbf{1 2 8}$ \\
\hline No. of generations & 2048 \\
Mutation rate & 0.35 \\
\hline
\end{tabular}

The GA is then applied to obtain the combination of factors that provides the best possible performance, according to the atmospheric and geographical conditions that prevail in Mexico City. The computational experiments were carried out on a workstation with 24 cores and 64 GB RAM and $3.1 \mathrm{GHz}$ processor. In these conditions, one execution lasts about $6 \mathrm{~h}$ so that 10 runs were performed for each working fluid, in order to evaluate the repeatability of the stochastic optimization technique for identifying consistent results.

The computational results show that the GA, depending on the working fluid considered, proposes different solutions. For each refrigerant, the GA proves a great robustness and consistently determines, for all 10 runs, similar solutions, where the yielded objective function, $O^{2}$, lies within $10^{-9}$ and $10^{-20}$ for all cases. This allows to say that the thermal capacity is almost equal to the optimal value $\tau_{C}=1$.

The four solutions found are thoroughly studied in order to identify any underlying features of the data obtained by the simulation of the DXSAHP, as functions of the optimized operation as well as the design factors.

First, Figures 18 and 19 illustrate the values of the decision variables, i.e., the work time, $\Delta t$, and the heat transfer area, $A_{E v a p}$, found by the optimizer throughout the year. In order to evaluate properly the results obtained, a statistical analysis is conducted and presented as follows.
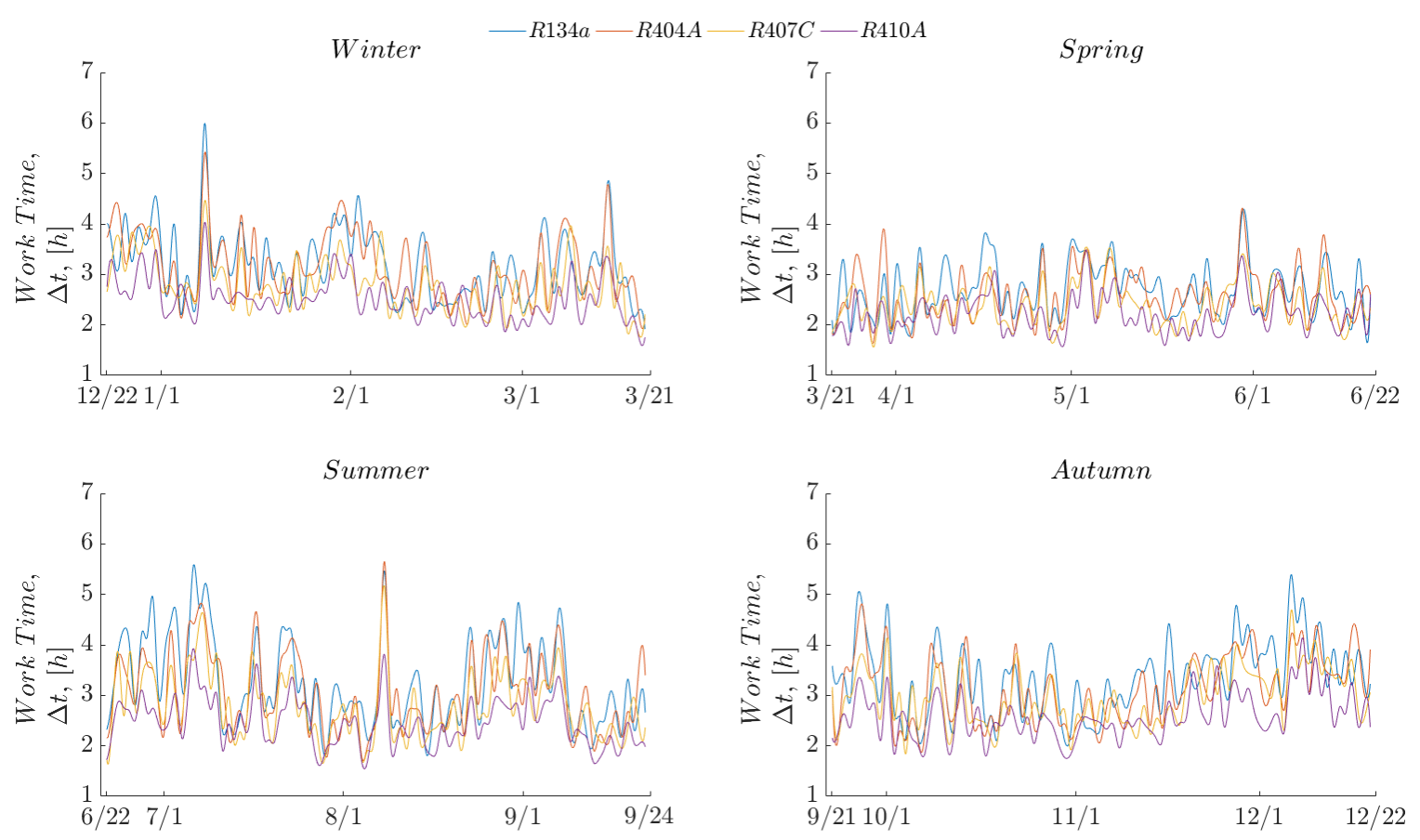

Figure 18. Work time optimization for all refrigerants. 

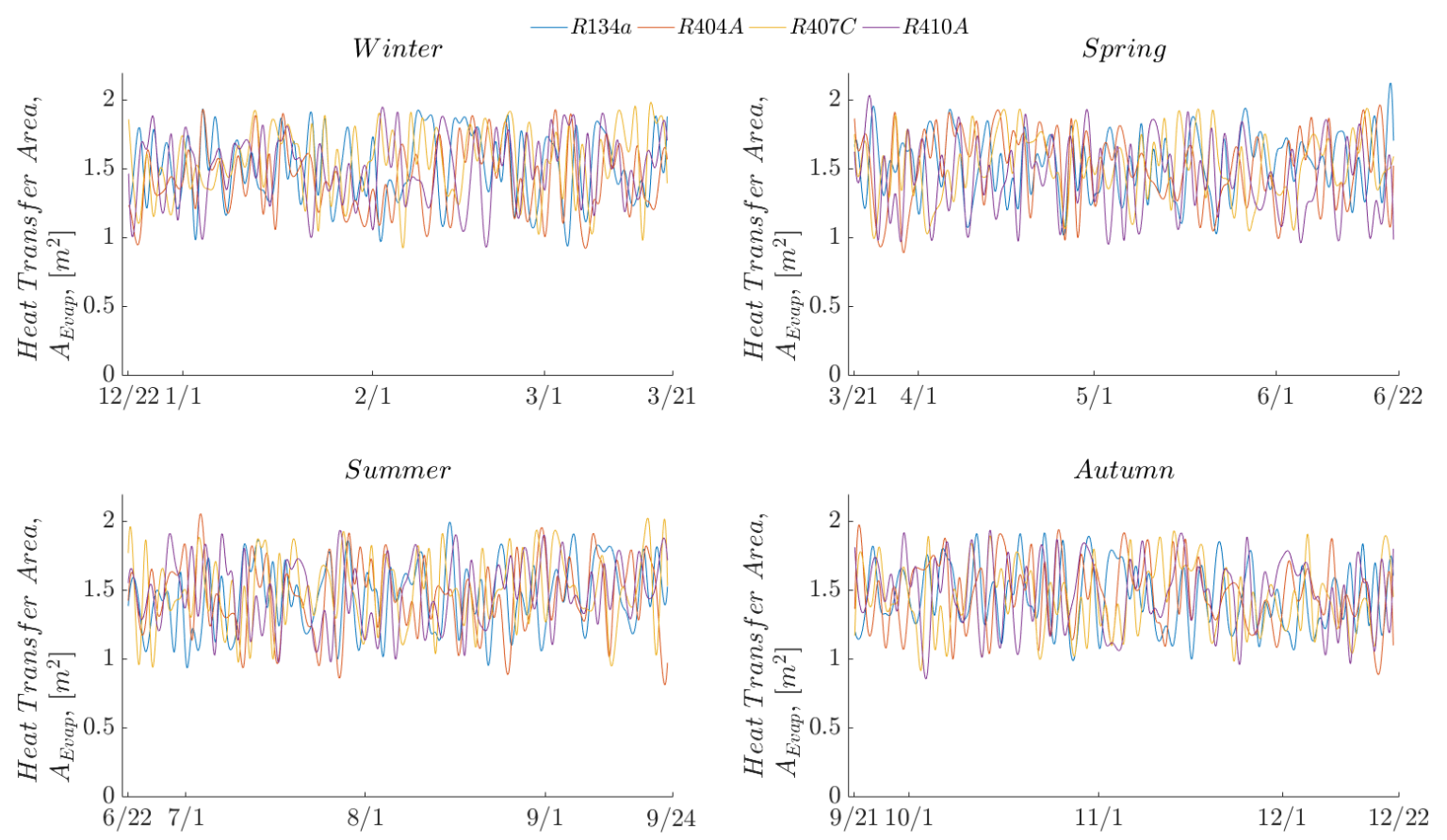

Figure 19. Heat transfer area optimization for all refrigerants.

Table 7 shows the main statistics describing the optimized decision variable datasets. These indicate, in a general manner, that the refrigerant influences the operation of the DXSAHP, with the average worktime throughout a whole year varying from $2.44 \mathrm{~h}$ for R410A to $3.13 \mathrm{~h}$ when using R134a. Similarly, the maximum working time is almost $6 \mathrm{~h}$ when employing R134a. Conversely, it decreases to a bit more than $4 \mathrm{~h}$ when using R410A, 22\% less. Meanwhile, the R404A and R407C refrigerant fluids, both show intermediate behaviours with a $5 \%$ and $12 \%$ decrease respectively compared to R134a.

Table 7. Main statistics of the optimized datasets.

\begin{tabular}{cccccc}
\hline $\begin{array}{c}\text { Optimized } \\
\text { Variables }\end{array}$ & Statistic & R134a & R404A & R407C & R410A \\
\hline & Count & 365 & 365 & 365 & 365 \\
& Mean & 3.13 & 2.98 & 2.74 & 2.44 \\
Work time & Standard deviation & 0.75 & 0.70 & 0.59 & 0.46 \\
& Coefficient of variation & $24.15 \%$ & $23.65 \%$ & $21.76 \%$ & $18.86 \%$ \\
& Minimum & 1.80 & 1.63 & 1.56 & 1.60 \\
& Maximum & 5.99 & 5.64 & 5.13 & 4.13 \\
& Range & 4.19 & 4.01 & 3.56 & 2.53 \\
\hline \multirow{2}{*}{ No. of } & Count & 365 & 365 & 365 & 365 \\
& Mean & 5.69 & 5.61 & 5.74 & 5.68 \\
& Ctandard deviation & 1.01 & 1.03 & 1.03 & 1.06 \\
& Coefficient of variation & $17.76 \%$ & $18.34 \%$ & $18.00 \%$ & $18.74 \%$ \\
& Minimum & 4.0 & 4.0 & 4.0 & 4.0 \\
& Maximum & 7.0 & 7.0 & 7.0 & 7.0 \\
& Range & 3.0 & 3.0 & 3.0 & 3.0 \\
\hline
\end{tabular}

Regarding the optimized heat transfer area, similar results are observed for all the datasets, despite the changing the working fluid. The average number of collectors required ranges from 5.61 to 5.74, equivalent to a heat transfer area of, approximately, $1.40 \mathrm{~m}^{2}$. For all the cases studied, the required number of collectors lies within the 4 to 7 range. The fact that this variable is not significantly affected by the working fluid can be attributed to the heat absorption of the DXSAHP system, which relies relatively more on the properties of the refrigerant than on the magnitude of the heat transfer area. 
In order to confirm the previous observations, an analysis of variances, ANOVA, is performed to evaluate the impact of the working fluid on the operation and design, i.e., work time and plate number, respectively.

Table 8 presents the results of evaluating the null hypothesis of similar inter-group means. Since, $p<0.05$ for the worktime, the null hypothesis is always rejected, meaning that there are significant differences between the samples. Nonetheless, regarding the number of collectors, for which $p>0.05$, the datasets do present similar mean values, within a $5 \%$ confidence level. Therefore, it can be inferred that the working fluid exerts a more significant effect on the work time of the heat pump than over the number of collectors.

Table 8. ANOVA of the optimized datasets.

\begin{tabular}{ccccccc}
\hline $\begin{array}{c}\text { Optimized } \\
\text { Variables }\end{array}$ & Source & Sum of Squares & $\begin{array}{c}\text { Degrees of } \\
\text { Freedom }\end{array}$ & $\begin{array}{c}\text { Squared } \\
\text { Means }\end{array}$ & F & $p$ Value \\
\hline \multirow{2}{*}{ Work time } & Inter-groups & 99.44 & 3 & 33.14 & 80.81 & 0.0000 \\
& Intra-groups & 597.23 & 1456 & 0.41 & - & - \\
& Total & 696.67 & 1459 & & - & 0 \\
\hline \multirow{2}{*}{ No. of } & Inter-groups & 3.10 & 3 & 1.03 & 0.97 & 0.4078 \\
collectors & Intra-groups & 1561.58 & 1456 & 1.07 & - & - \\
& Total & 1564.69 & 1459 & & - & - \\
\hline
\end{tabular}

Figure 20 shows the relative frequency of the samples observed after the optimization, corroborating clearly different distributions for both decision variables. The worktime, $\Delta t$, based on the refrigerant, displays an evident reduction. Diversely, it is seen that there are no significant changes in the number of evaporation plates: where the R134a presents a slight trend to use only 4 collectors, the R404A to use 5, and refrigerants R407C and R410A to use between 5.5 to 6 plates.

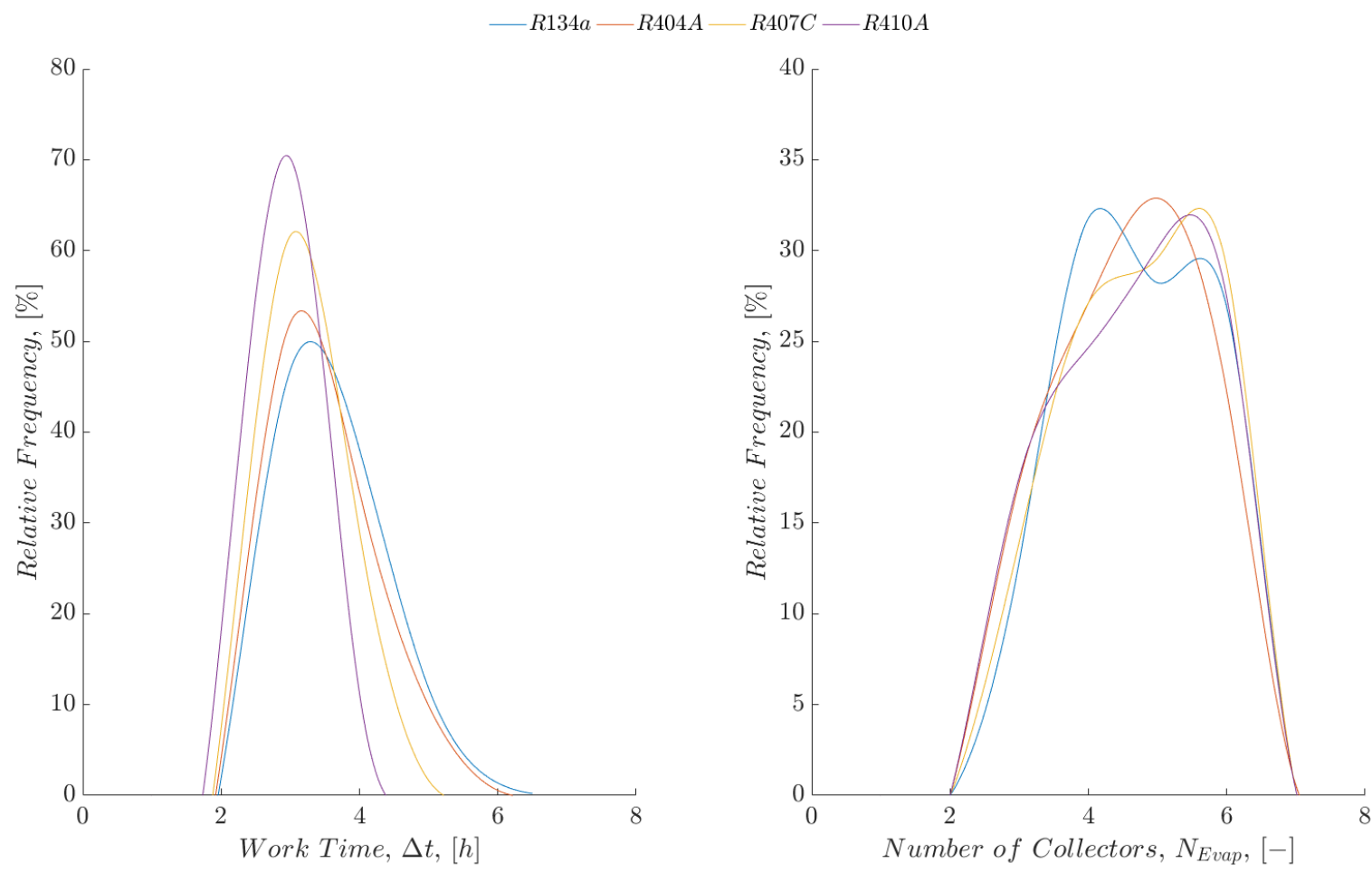

Figure 20. Relative frequency of the optimization products.

To complement this analysis, Figure 21 shows the PDE of the products obtained from the above optimization process, based on the statistics describing their behaviour. 

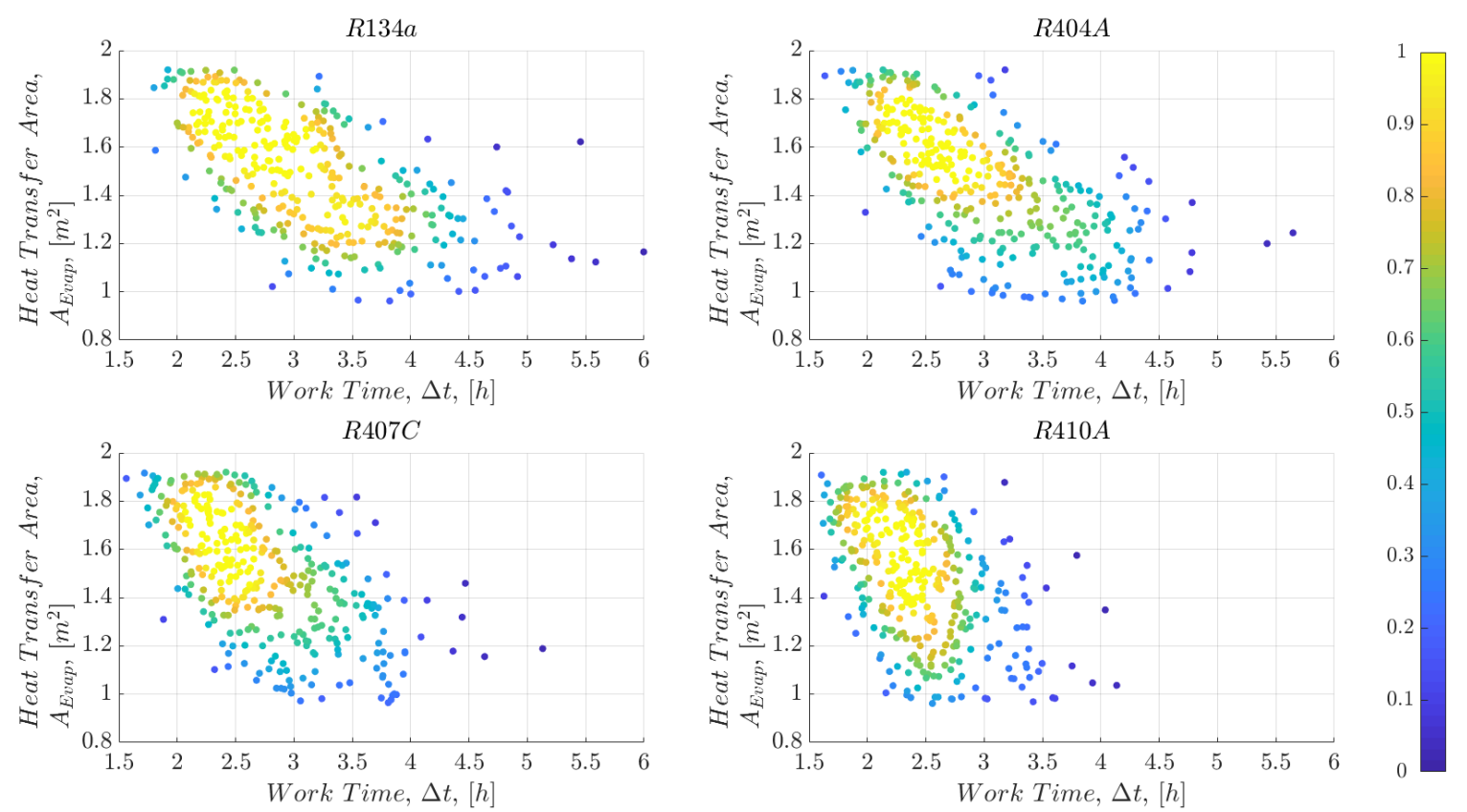

Figure 21. Probability density estimation of the optimization products for all refrigerants.

Overall, the highest density, regarding the heat transfer area, maintains a range between $1.2 \mathrm{~m}^{2}$ and $1.8 \mathrm{~m}^{2}$ for all refrigerant fluids, confirmed by the similarity between the coefficients of variation. Meanwhile, the dataset corresponding to the optimized worktime is concentrated between 2 and $4 \mathrm{~h}$, with pronounced variations depending on working fluid.

From this, it is corroborated that the refrigerant R134a is capable of operating with smaller heat transfer areas, 5.5 to 7 panels, at the expense of an increase in the work time range, between 2 and $4 \mathrm{~h}$. Diversely, R410A presents less dispersion among the samples which translates to more defined operation conditions, where 6 and 7 evaporation units are to be employed and a reduction in the work time range ensues, equal to approximately $1.5 \mathrm{~h}$.

Regarding the R404A and R407C refrigerants, they maintain similar trends; intermediate compared the remaining working fluids, being $\mathrm{R} 407 \mathrm{C}$ the one that presents the lowest dispersion rate and less isolated occurrences, alongside a slight decrease of the work time.

\subsection{Optimized Energy Exchange Rate}

Figure 22 shows the condensation heat rate, $\dot{Q}_{C}$, of the DXSAHP system based on the results obtained through the optimization. It is seen that the R410A refrigerant has a higher heat transfer rate than the remaining refrigerants, with an annual average of $5.38 \mathrm{~kW}$, and seasonal heat rate variations of $2 \%$. This is followed by $\mathrm{R} 407 \mathrm{C}$ with an average heat rate of $4.86 \mathrm{~kW}$ and a seasonal variation of $4 \%$; R404A with an average $4.49 \mathrm{~kW}$ and a variation of 3\% and, finally, R134a with an average annual heat rate of $4.3 \mathrm{~kW}$ and a seasonal variation of $4 \%$.

Similarly, Figure 23 illustrates the compression power input, $\dot{W}_{C}$, highlighting that, for all refrigerants, this parameter remains relatively constant throughout the year, with seasonal variations between 1.5 and $2.5 \%$. In addition, it is seen that R134a is the refrigerant that requires the lowest power input, with $0.40 \mathrm{~kW}$, followed by R407C with $0.65 \mathrm{~kW}$, R404A with $0.72 \mathrm{~kW}$ and R410A with $1.06 \mathrm{~kW}$, equivalent to respective increments of $62 \%, 80 \%$ and $165 \%$ compared to the work required by the R134a working fluid. 

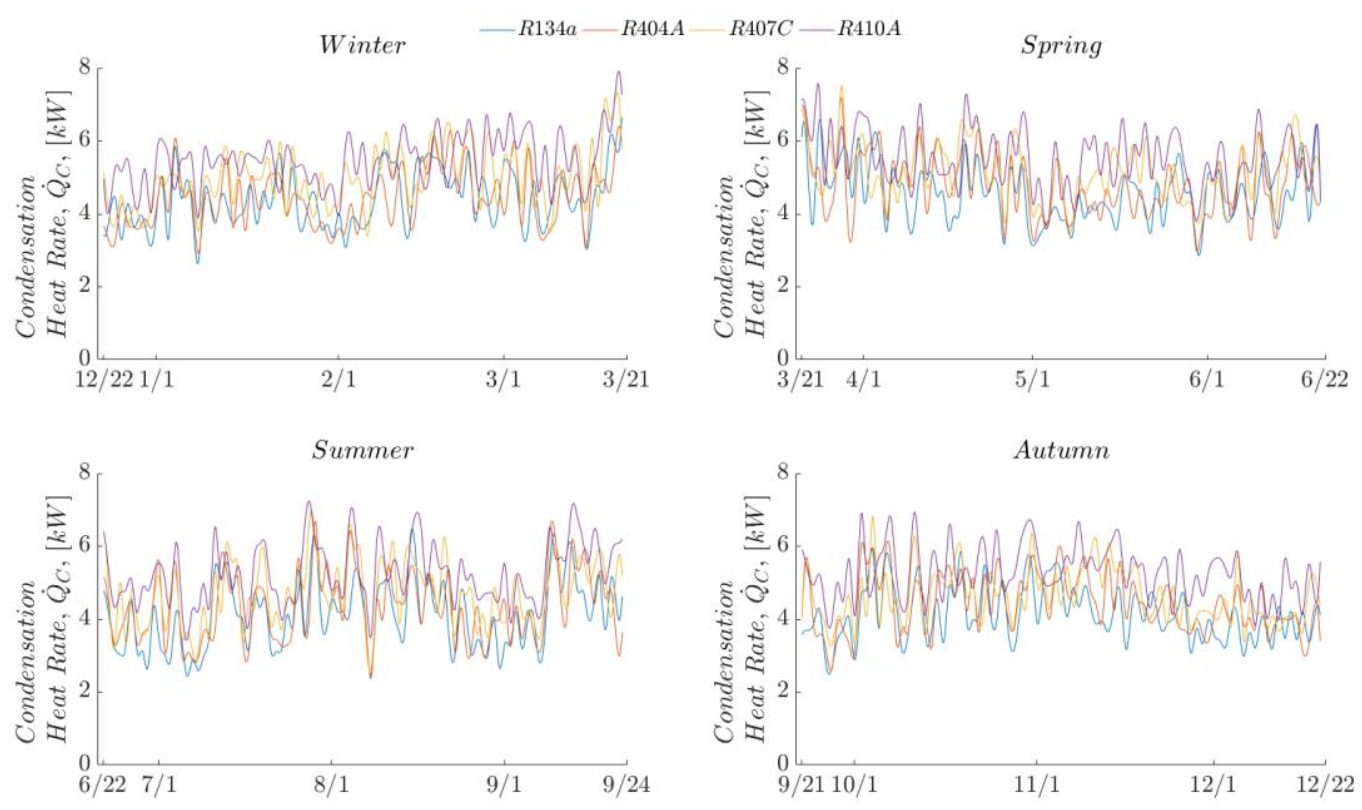

Figure 22. Seasonal condensation heat rate of the optimized system for all refrigerants.
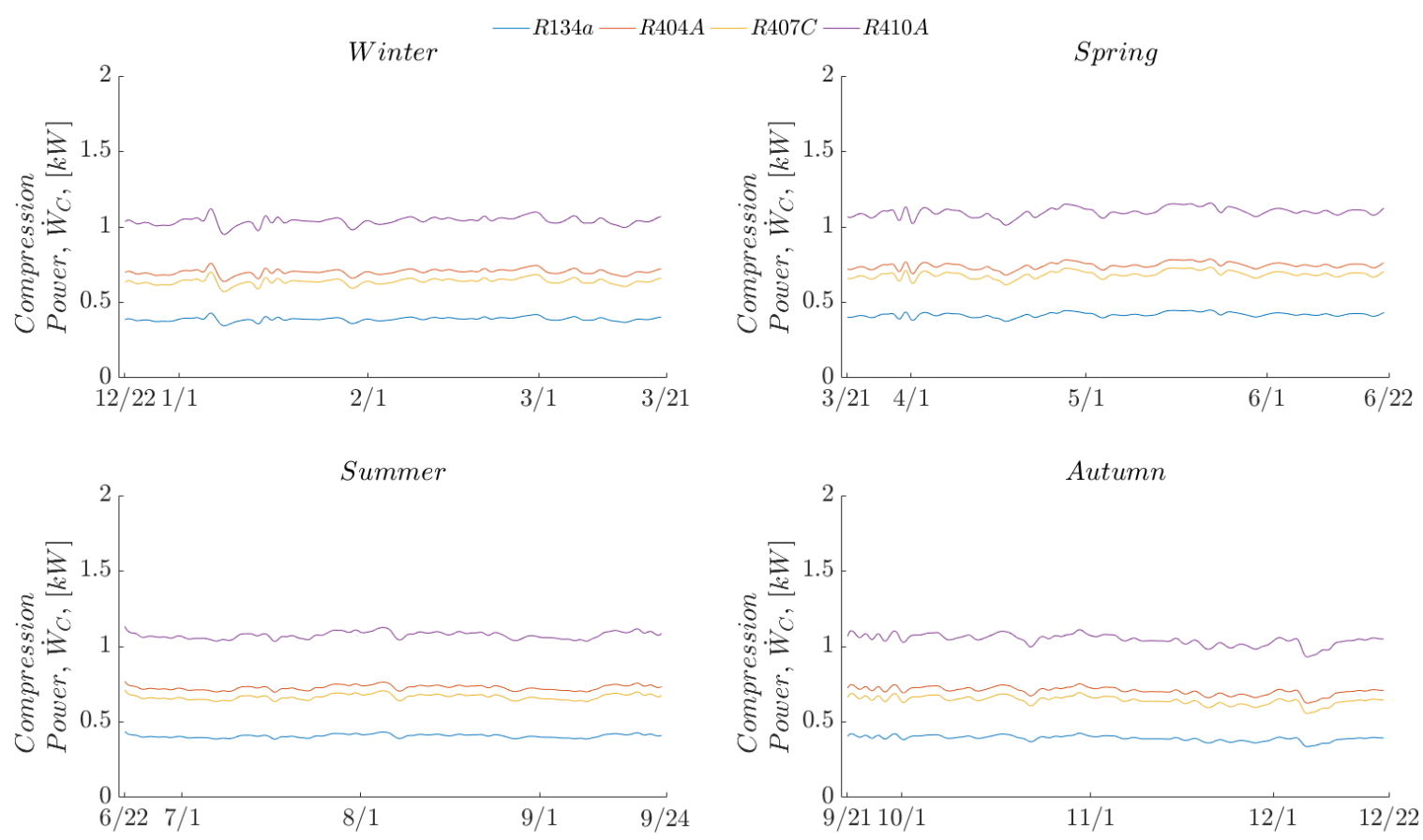

Figure 23. Seasonal compression power input of the optimized system for all refrigerants.

Based on the presented variations, it is inferred that the implementation of the optimization reduces the fluctuations that occur throughout the year, with a decrease in the maximum seasonal variations of $6 \%$ for the heat rate $\dot{Q}_{C}$ and of $2 \%$ for the compression power input, $\dot{W}_{C}$. The final design is thus more stable and provides a more consistent operation and performance levels.

In order to enhance the analysis, Figures 24 and 25 show the relative frequency of the energy exchange of the DXSAHP as a function of the optimized products. 


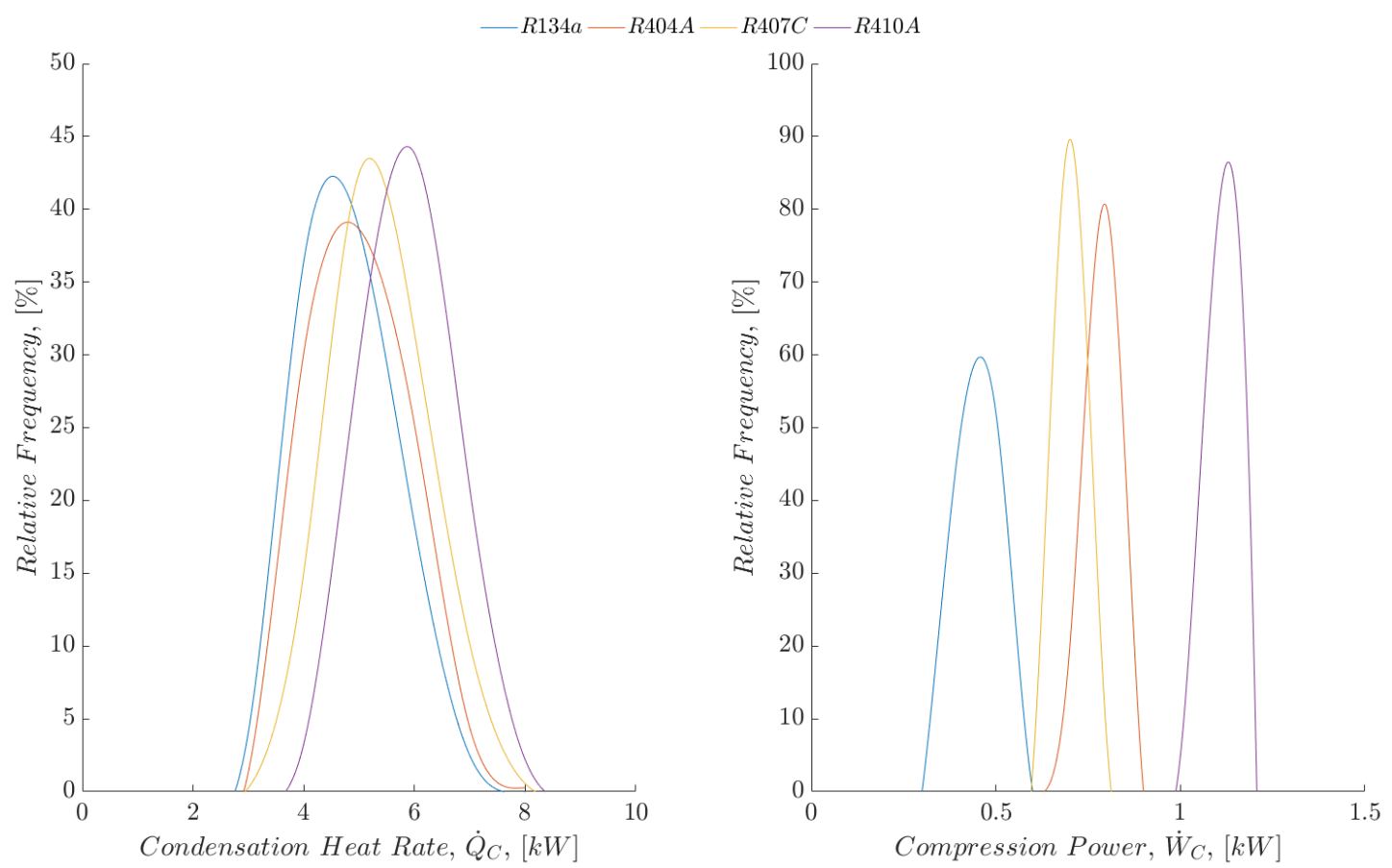

Figure 24. Relative frequency of the energy exchange of the optimized system for all refrigerants.

$\circ R 134 a$ 口 $R 404 A \triangle R 407 C \backsim R 410 A$
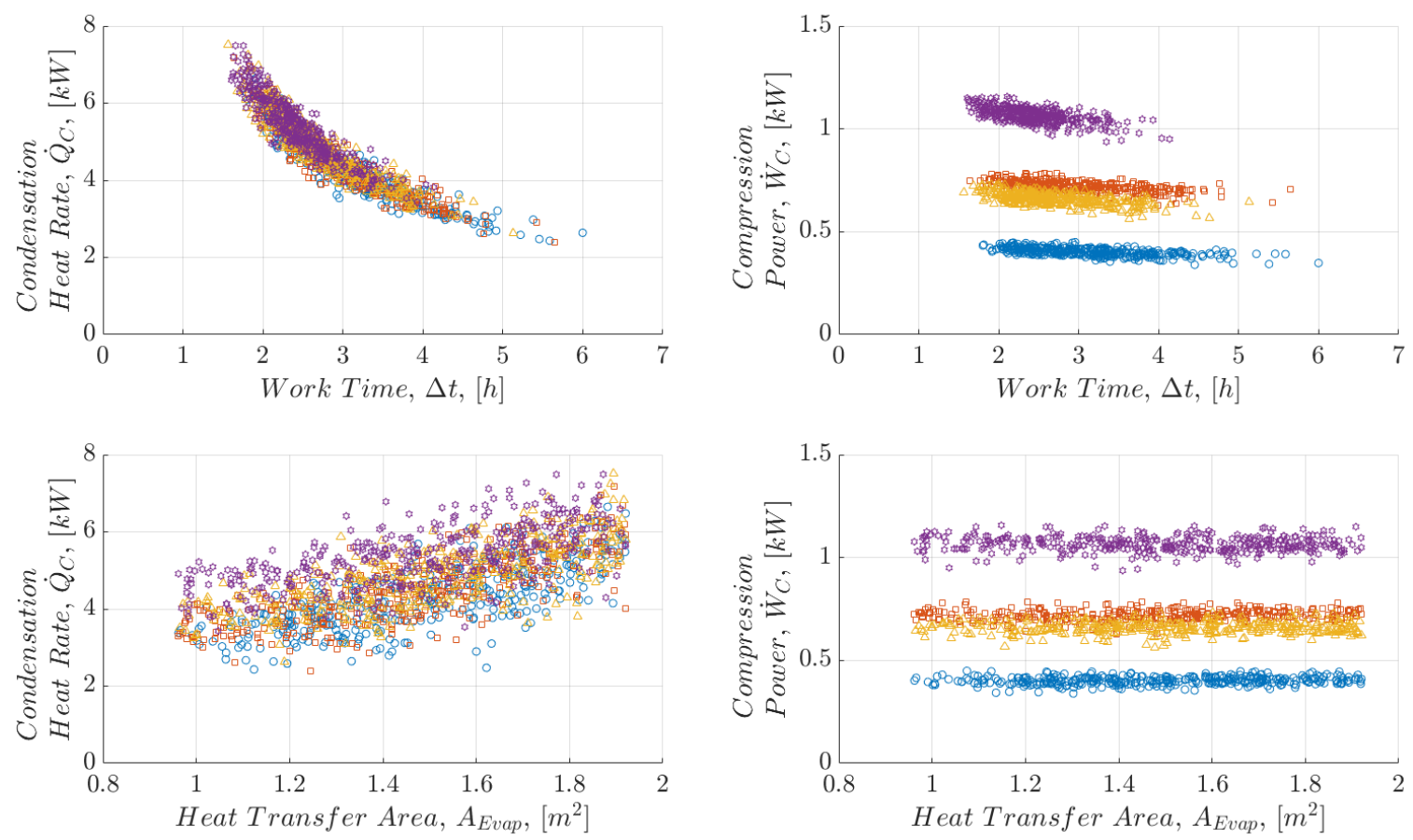

Figure 25. Performance of the optimized DXSAHP system based on the energy exchange.

In Figure 24, refrigerants R134a and R410A tend to have, respectively, the lowest and highest compression work input required, as well as the lowest and highest condensation heat rates. Meanwhile, the remaining working fluids, R404A and R407C, provide the DXSAHP with a more moderate and consistent energy exchange, being the R407C refrigerant slightly better than the R404A, due to a lower compression work required and a higher heat transfer rate.

Figure 25 corroborates all the information presented so far, where the performances of the refrigerants are evaluated as a function of the evaporation area and the work time. It is observed that 
the working fluid does not directly and significantly influence the magnitude of the evaporation area. However, it does have an impact on the work time, through the energy exchange, since R410A is able to yield a higher heat supply to the water, while reducing operation times, at the expense of an increase of the compression work input. Moreover, it is seen that the R134a can compensate the difference in heat flow, compared to the R410A, by increasing the evaporation area where, approximately, every $0.25 \mathrm{~m}^{2}$ represents $1 \mathrm{~kW}$ more energy.

Furthermore, as stated before, $\mathrm{R} 407 \mathrm{C}$ is slightly more effective than R404A, because it tends to provide more heat and require less work than the latter, which leads to a reduction in work time of just under an hour.

\subsection{Optimized Coefficient of Performance}

From the information obtained in the previous section, it is possible to determine the COP in order to select the refrigerant that provides the DXSAHP with the highest performance available.

In Figure 26, it is seen that the R134a refrigerant is the one that presents the highest COP, since it requires the lowest compression power, reaching an annual average of 10.68 , followed by R407C with 7.37, R404A with 6.23 and finally R410A with 5.05. These values represent decreases of $31 \%, 42 \%$ and $52 \%$, respectively.
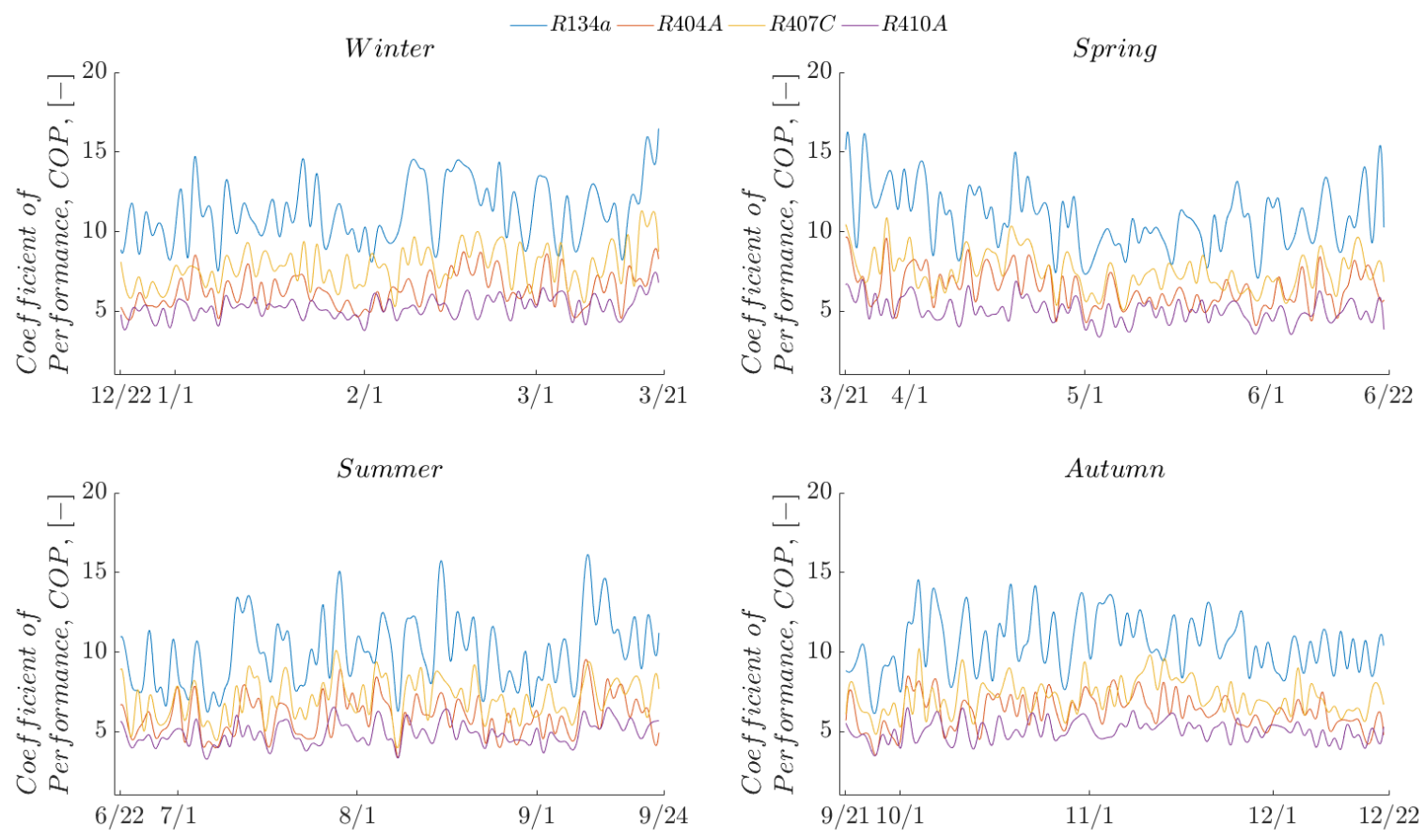

Figure 26. Seasonal coefficient of performance of the optimized system for all refrigerants.

In addition, as shown in Table 9, R134a is the one that shows the widest range and the highest coefficient of variation, which indicates that this working fluid is the most susceptible to changes in atmospheric conditions and consequently to the energy exchange of the system. Alternatively, R410A provides a more consistent performance having a lower coefficient of variation, which results in a high degree of tolerance to climate fluctuations, due to its higher heat transfer capabilities. Meanwhile, the remaining refrigerants present intermediate characteristics, with R407C being slightly better. 
Table 9. Main statistics of the optimized coefficient of performance.

\begin{tabular}{ccccc}
\hline Statistic & R134a & R404A & R407C & R410A \\
\hline Count & 365 & 365 & 365 & 365 \\
Mean & 10.68 & 6.23 & 7.37 & 5.05 \\
Standard deviation & 1.98 & 1.15 & 1.23 & 0.70 \\
Coefficient of variation & $18.62 \%$ & $18.53 \%$ & $16.71 \%$ & $14.00 \%$ \\
Minimum & 6.21 & 3.38 & 4.08 & 3.29 \\
Maximum & 16.47 & 9.62 & 11.18 & 7.11 \\
Range & 10.25 & 6.23 & 7.10 & 3.82 \\
\hline
\end{tabular}

From this information, Figure 27 is presented. It shows the relative frequency of the performance coefficient as a function of the different refrigerants. This figure shows the trend of each refrigerant and corroborates the aforementioned behaviour, based on both its magnitude range and the coefficient of variation.

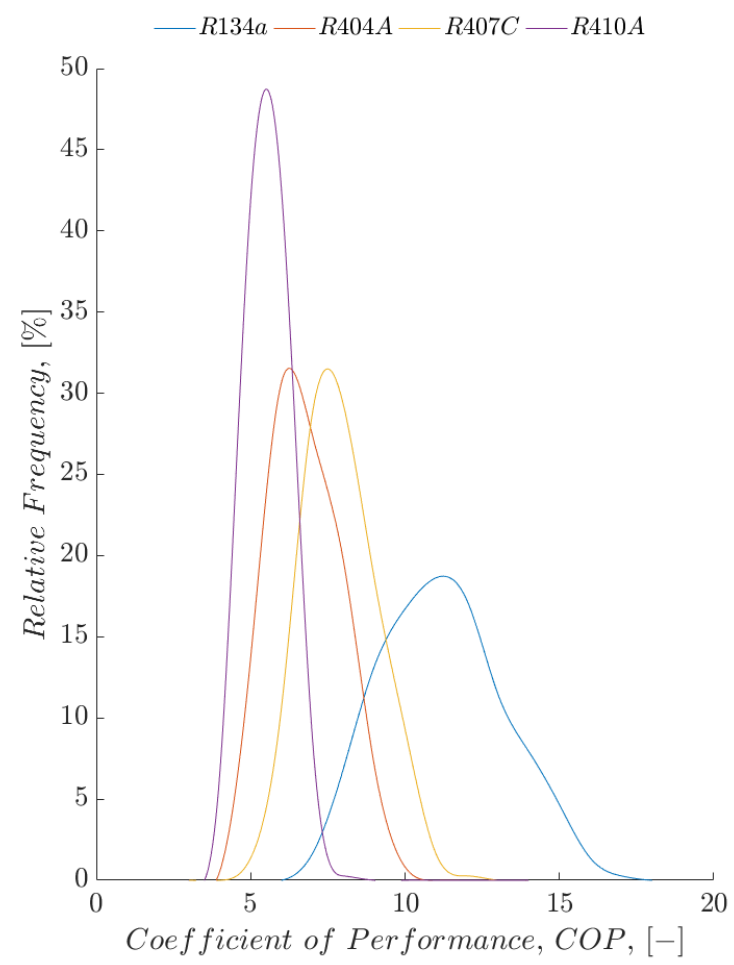

Figure 27. Relative frequency of the COP of the optimized system for all refrigerants.

Finally, Figures 28 and 29 describe the performance trend of the DXSAHP system as a function of both, the optimized worktime and heat transfer area, by means of the estimation of the density of the probability function.

These figures highlight the fact that the R134a refrigerant exhibits the greatest dispersion of all datasets. However, this refrigerant delivers the highest COP and the longest work time of all the analysed data, with a range of 9 to 12 , and 2.5 to $3.5 \mathrm{~h}$ respectively, while the heat transfer area is concentrated between 1.2 and $1.8 \mathrm{~m}^{2}$, equivalent to a number of evaporation units ranging 5 to 7.5 . 

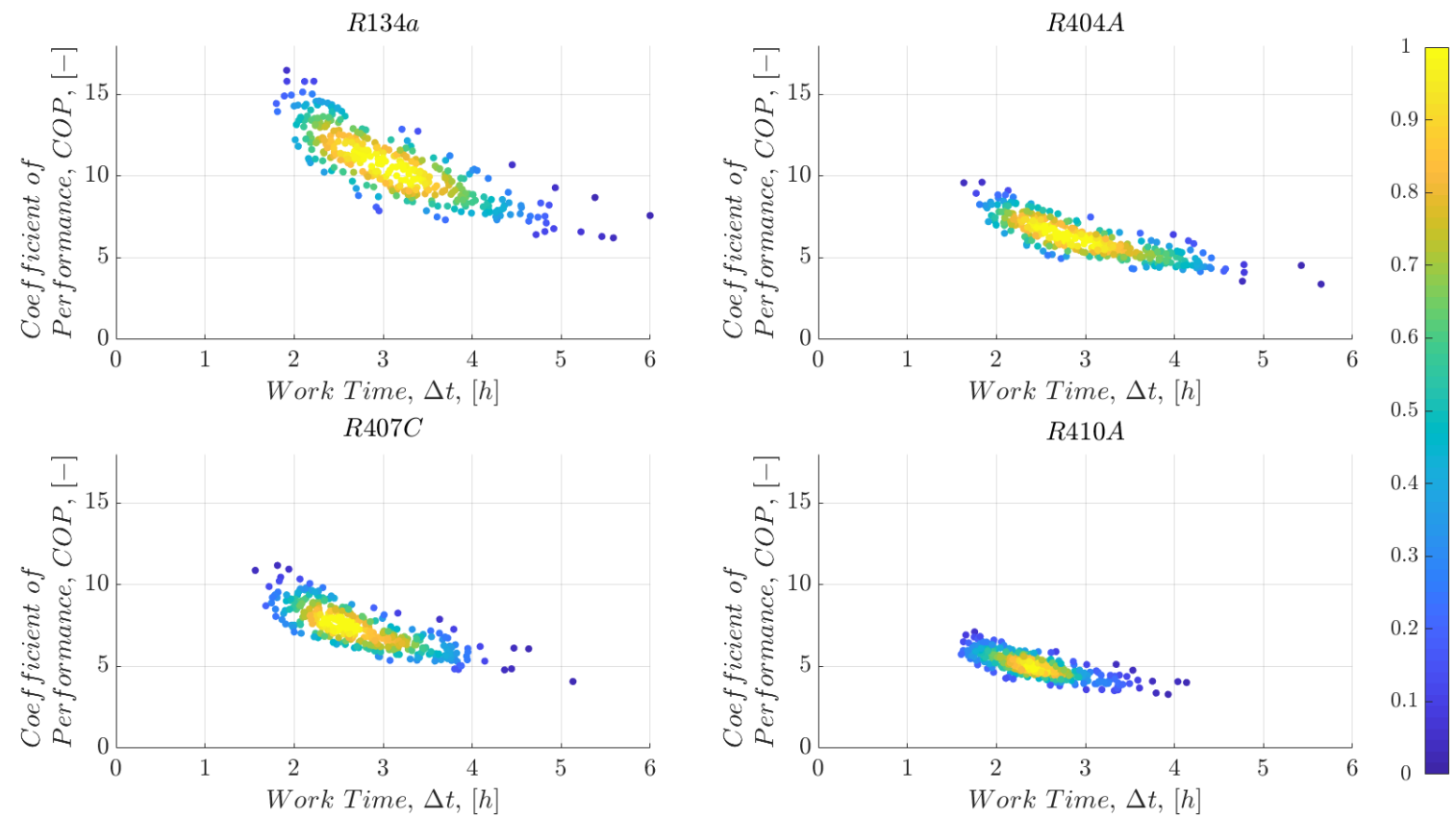

Figure 28. Probability density estimation of the work time as a function of the coefficient of performance for all the working fluids employed.
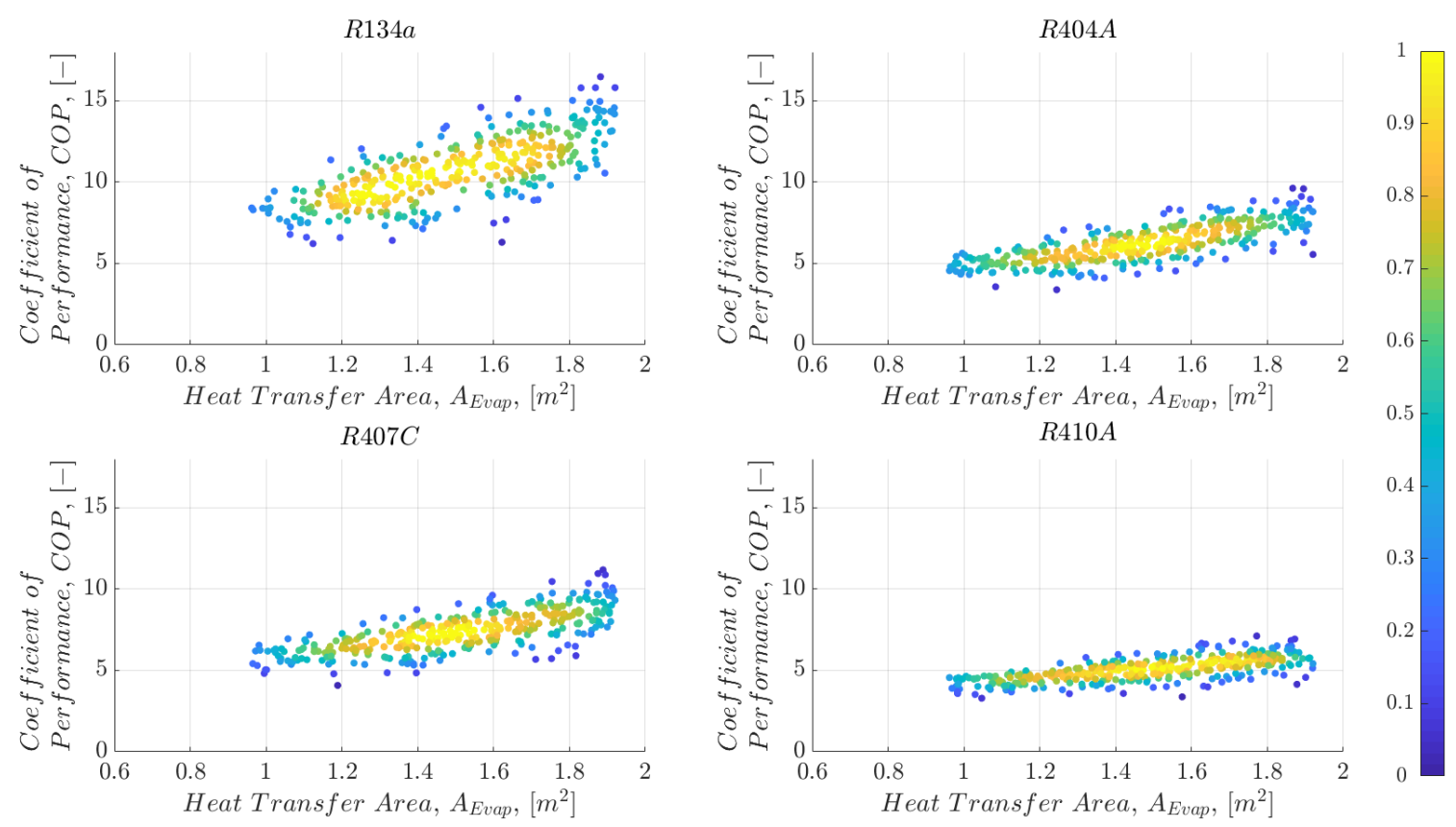

Figure 29. Probability density estimation of the heat transfer area as a function of the coefficient of performance for all the working fluids employed.

The R404A refrigerant has a worktime range of 2.5 to $3 \mathrm{~h}$ and, compared to R134a, a reduction in both the ranges of the heat transfer area and of the COP, with magnitudes reaching between 1.4 to $1.6 \mathrm{~m}^{2}$ and 5.5 to 8 , respectively.

This behaviour is relatively analogous for the R407C refrigerant, for which the concentration of data indicates a range in both heat transfer area and COP of 1.3 to $1.6 \mathrm{~m}^{2}$ and 6 to 9 respectively, with the advantage that the work time is concentrated around $2.5 \mathrm{~h}$.

Finally, R410A exhibits the least dispersion of the refrigerants, with a $2.5 \mathrm{~h}$ worktime and a range of heat transfer area from 1.4 to $1.6 \mathrm{~m}^{2}$. Meanwhile, COP levels range between 4 and 6 , which 
represents a significant decrease compared to R134a equivalent to approximately $50 \%$ and $25 \%$ relative to both the R404A and R407C refrigerants, making it the coolant with the lowest performance of the studied samples.

From the presented analysis, and based on the literature review, it is concluded that regardless of the fluctuations in the COP for the different working fluids studied, all of them maintain levels higher than, or equal to, the average, generally exhibited by conventional heat pump cycles. This is due to both to the advantageous atmospheric conditions of Mexico City, as well as to the system design. In addition, this analysis provides guidelines for the appropriate selection of a working fluid. For this particular case, is R407C is deemed the most suitable, since; it shows a lower dispersion of the samples and provides the DXSAHP with a consistent and regular performance. This working fluid performs without the drastic reduction of the COP presented by R410A or the increase in heat transfer area, consequence of using R134a. Consequently, a worktime decrease equivalent to 1 hour, relative to both R134a and R404A is achieved, reducing the overall energy consumption of the system.

\section{Conclusions and Outlook}

The analysis and optimization of a DXSAHP as a domestic heat water system was carried out using as a foundation the thermal capacity of the system, a 10-year database of the atmospheric conditions in Mexico City and a genetic algorithm as an optimization technique. Explicit design specifications are provided to conduct a simulation of the corresponding system behaviour and its subsequent optimization; the conclusions are presented as follows.

Based on the computed thermal capacity, the feasibility study conducted reflects that, depending on the working fluid selected, a minimum heat transfer area, $A_{\text {Evap }}$ from 1 to $2 \mathrm{~m}^{2}$ and at least 3.5 to $5 \mathrm{~h}$ of worktime, $\Delta t$, are required. Therefore, given the advantageous weather conditions that prevail in the region, i.e., high solar radiation, high ambient temperature, the potential installation and operation of DXSAHP-based water heating systems in Mexico City is concluded plausible.

Based on the obtained results it is concluded that the R410A refrigerant presents the highest heat transfer capabilities, yielding an average condensation heat rate of $6.31 \mathrm{~kW}$, followed by the R407C with $5.72 \mathrm{~kW}$, the R404A with $5.42 \mathrm{~kW}$ and the R134a with $5.18 \mathrm{~kW}$. Conversely, the R134a refrigerant requires the lowest compression work input, $0.402 \mathrm{~kW}, 62 \%$ less than the R410A, which requires $1.06 \mathrm{~kW}$, whilst the $\mathrm{R} 404 \mathrm{~A}$ and $\mathrm{R} 407 \mathrm{C}$ fluids, present a more moderate energy consumption with 0.66 and $0.58 \mathrm{~kW}$ respectively.

Regarding the performance of the system, based on the overall energy exchange throughout the year, it is concluded that, despite changes on weather or design conditions, all refrigerants perform within or beyond the minimum expected performance range, with COP levels higher than 3.

Specifically, it is observed that R134a delivers the highest COP, ranging from 7 to 14 , but tends to require the maximum heat transfer area available, between 7 and 8 evaporation panels, and at least $5 \mathrm{~h}$ of worktime. Diversely, the R410A refrigerant provides the DXSAHP with the lowest COP range; from 3.5 to 6.5 , which is almost half of R134a, but in turn, is able to work with only 4 evaporation panels and to heat the product $20 \%$ faster, within a 3.5 to $4 \mathrm{~h}$ range. This feature results majorly convenient when indirect external factors, such as space availability and installation costs, may influence the overall design of the DXSAHP. Meanwhile, refrigerants R404A and R407C show particularly similar behaviours, with COP levels ranging from 4 to 8.5 and 5 to 10 respectively. Additionally, both are able to heat $300 \mathrm{~L}$ of water in 4 to $4.5 \mathrm{~h}$ with a minimum heat transfer area equivalent to 5 to 6 evaporators, all while yielding a more moderate response towards design and indirect external factors compared to the remaining refrigerants.

Therefore, based on the thermal behaviour of the working fluids, it is concluded that R134a should be employed when energy consumption is a priority, thermal demand is low to moderate and worktime is not an issue; R410A is recommended when space availability is limited and a lesser number of collectors are required. Meanwhile, the remaining R404A and R407C should be preferred when the aforementioned conditions are not constrains and a steadier operation scheme is needed. 
Based on the thermal capacity analysis, it is seen that throughout the year, the heat pump maintains a relatively high condensation heat flow, $\dot{Q}_{C}$, within a range of 4 to $8 \mathrm{~kW}$, while the thermal load required, $\dot{q}_{T}$, varies between seasons inside a 2.5 to $3.5 \mathrm{~kW}$ range, i.e., 1 refrigeration ton or lower, with the lower bounds corresponding to spring and summer seasons. Therefore, it is concluded that the atmospheric conditions of Mexico City are particularly advantageous. Given the high radiation and ambient temperature as well as the low-moderate thermal demand it is seen that the HP system is capable of yielding more than twice the heat required. This is corroborated with thermal capacity levels ranging from 0.9 to 2.5 depending on the working fluid and the number of evaporators installed.

This evaluation should be complemented with a probability density estimation, or any other statistical assessment tool, in order to properly identify the underlying features, i.e. trend, of the system behaviour and thus propose adequate setups.

Based on this statistical analysis, it is highlighted that the R134a shows a higher dispersion of the data, which results in a major number of outlier events throughout the year. Thus, concluding that R134a is the most susceptible working fluid to immediate external factors, such as weather and seasonal changes, while the remaining refrigerants present a more consistent behaviour due to their heat transfer capabilities.

Nonetheless, based on the aforementioned information, it is seen that the performance assessment alone does not categorically determines the best combination of parameters, given that the selection of the working fluid depends mostly on the operation conditions imposed by the end user. Hence, it is concluded that an optimization of the system is required in order to make an integral evaluation.

The optimization carried out in this paper employed a well-known technique, i.e., genetic algorithm, and identified those parameter configurations leading to thermal capacities approximately equal to 1, which allow an optimal use of the resources, whilst ensuring that the required output conditions are achieved.

From the data obtained through the optimization, it is seen that the overall performance of the HP improved, based on a reduction of the average worktime from a maximum of 5 to $3.5 \mathrm{~h}$, as well as a reduction on the maximum heat transfer area required, from 8 to 6 evaporators.

After the optimization, the proposed working fluids exhibit the following improvements:

- R134a refrigerant presented a 30\% reduction in the worktime, from 5 to $3.5 \mathrm{~h}$, and an average $20 \%$ reduction in the average heat transfer area, which resulted in a COP range of 9 to 12.

- $\quad$ R404A refrigerant reduced $12 \%$ the worktime and $2 \%$ the average heat transfer area achieving COP levels of 5.5 to 8.

- R407C refrigerant decreased the worktime needed by $41 \%$ and the average heat transfer area by $4 \%$, reaching COP levels of 6 to 9 .

- R410A refrigerant shortened the worktime 33\% and minimized the average heat transfer area by $1 \%$, presenting COP levels between 4 and 6 .

From this, it is concluded that, using R407C as a working fluid results in the best performance available for the DXSAHP. The resulting heat transfer area is equivalent to 5.5 evaporation units, an average $31 \%$ reduction compared to the $\mathrm{R} 134 \mathrm{a}$, and a decrease of 1 to $1.5 \mathrm{~h}$ on the worktime needed to reach the desired output conditions. Moreover, R407C reaches an average COP of 7.5 that, even though is $40 \%$ lower than R134a, is still $30 \%$ and $20 \%$ higher than the R410A and R404A respectively.

Furthermore, the implementation of the optimization yielded a convergence of data towards a single optimal operation point, therefore, is concluded that the evolutionary solution technique is adequate and efficient for the analysis of these systems, thus its popularity and common implementation. Additionally, it was found that this technique is flexible enough to work with design specifications that should be determined considering the fluctuations in the atmospheric conditions while operating.

Finally, in order to increase its effectiveness, as perspective for future work, more design and operation variables might be considered by the optimizer, such as the capacity of the thermal storage unit, the pressure drop inside the collectors-evaporators, its material and their corresponding 
thermophysical properties, the refrigerant charge, among others. Another proposed research line consists in hybridizing the genetic algorithm with an artificial neural network, ANN, which would replace the simulation tool, in order reduce CPU times and increase the efficiency for solving more complex optimization problems, such as the above-mentioned.

Author Contributions: Conceptualization, J.E.D.L.-R. and I.C.-M.; Data curation, J.E.D.L.-R.; Formal analysis, J.E.DL-R.,I.C.-M. and A.P.; Investigation, J.E.D.L.-R.; Methodology, J.E.D.L.-R., I.C.-M. and A.P.; Resources, I.C.-M. and A.P.; Software, J.E.D.L.-R. and A.P.; Supervision, I.C.-M. and A.P.; Validation, J.E.D.L.-R., I.C.-M. and A.P.; Visualization, J.E.D.L.-R.; Writing—original draft, J.E.D.L.-R.; Writing—review \& editing, I.C.-M. and A.P.

Funding: The research work described in this paper was fully supported by the grants from the National Council of Science and Technology of Mexico and the resources provided by the Applied Thermal and Hydraulic Engineering Laboratory of the National Polytechnic Institute of Mexico.

Conflicts of Interest: The authors declare no conflict of interest. The founding sponsors had a role in the decision to publish the results, but not in the design of the study, in the collection, analyses, or interpretation of data and in the writing of the manuscript.

\section{Nomenclature}

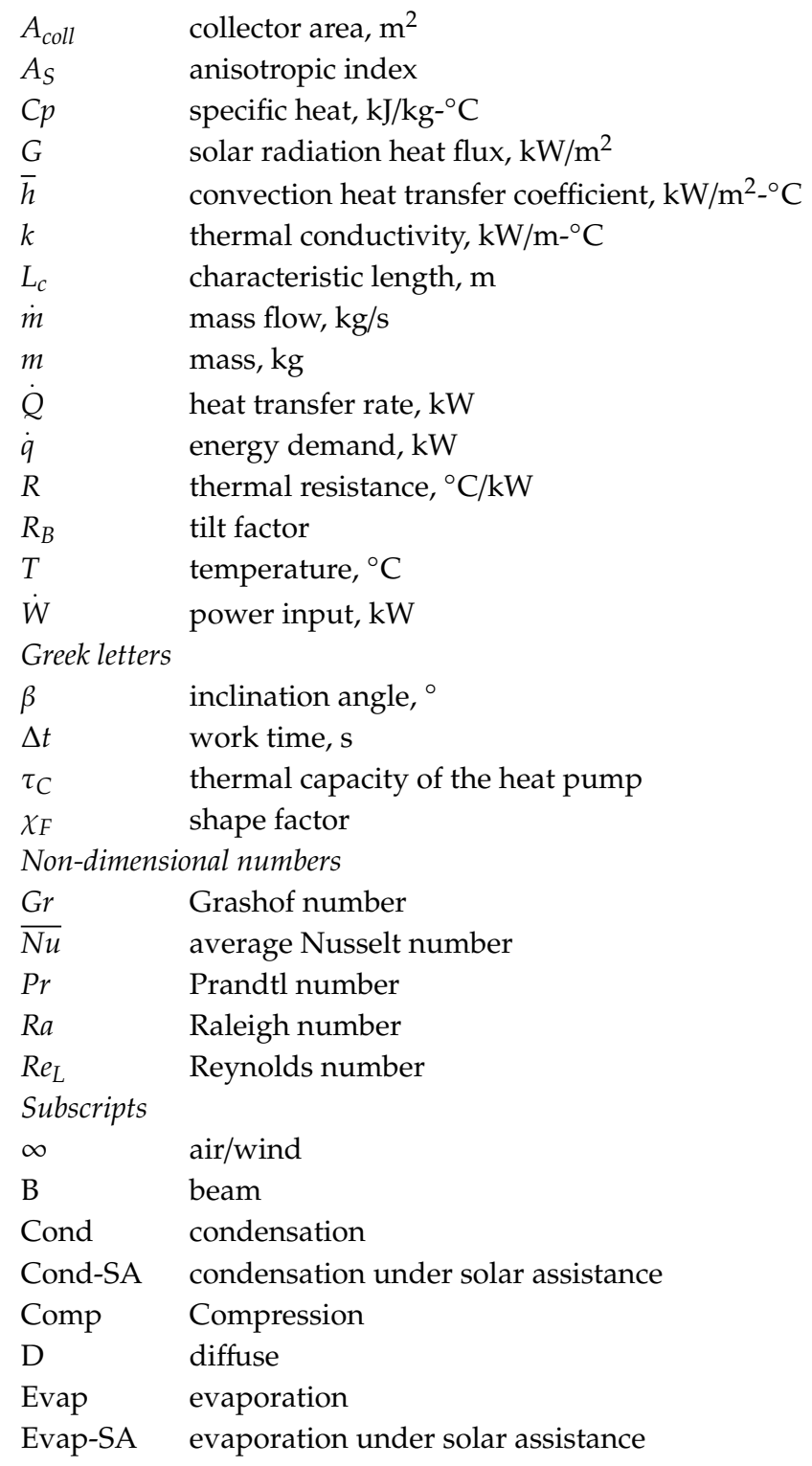




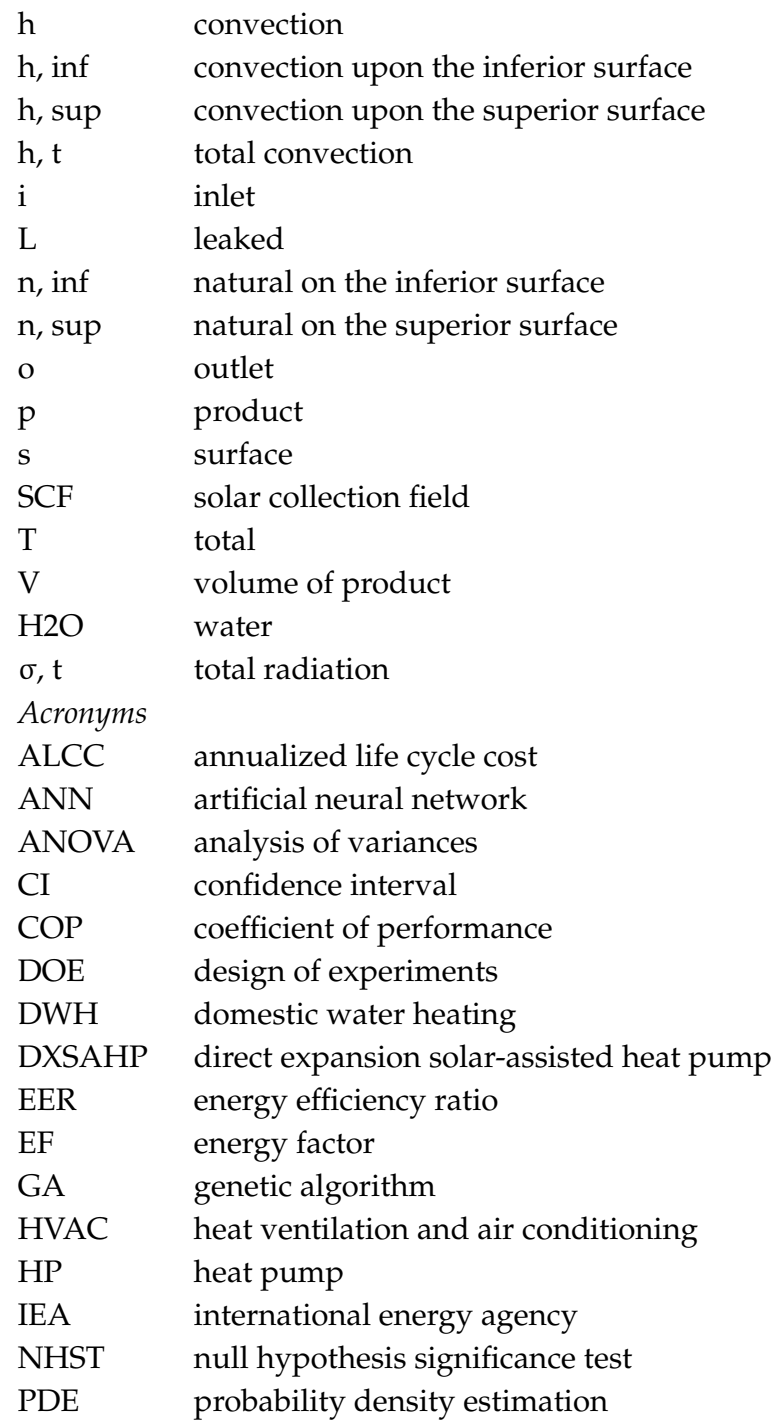

\section{References}

1. Staffell, I.; Brett, D.; Brandon, N.; Hawkes, A. A Review of Domestic Heat Pumps. Energy Environ. Sci. 2012, 5, 9291-9306. [CrossRef]

2. International Energy Agency. World Energy Outlook 2018; IEA Publications: Paris, France, 2018.

3. European Photovoltaic Industry Association. Global Market Outlook 2019; Solar Power Europe: Brussels, Belgium, 2015.

4. Chaturvedi, S.K.; Chiang, Y.F.; Roberts, A.S., Jr. Analysis of a Two-Phase Flow Solar Collectors with Application to Heat Pumps. J. Sol. Energy Eng. 1982, 104, 358-365. [CrossRef]

5. Chaturvedi, S.K.; Shen, J.Y. Thermal Performance of a Direct Expansion Solar-Assisted Heat Pump. Sol. Energy 1984, 33, 155-162. [CrossRef]

6. Moreno-Rodríguez, A.; González-Gil, A.; Izquierdo, M.; García-Hernando, N. Theoretical Model and Experimental Vlidation of a Direct Expansion Solar-Assisted Heat Pump for Domestic Hot Water Applications. Energy 2012, 45, 704-715. [CrossRef]

7. Moreno-Rodríguez, A. Experimental Validation of a Theoretical Model for a Direct Expansion Solar-Assisted Heat Pump Applied to Heating. Energy 2013, 60, 242-253. [CrossRef]

8. Cutic, T.; Pasanec, J.; Baleta, J.; Soldo, V.; Curko, T. Mobile Solar-Assisted Heat Pump with Direct Expansion. In Proceedings of the EuroSun 2012-ISES Europe Solar Conference, Rijeka, Croatia, 18-20 September 2012.

9. Li, Y.W.; Wang, R.Z.; Wu, J.Y.; Xu, Y.X. Experimental Performance Analysis on a Direct-Expansion Solar-Assisted Heat Pump Water Heater. Appl. Therm. Eng. 2007, 27, 2858-2868. [CrossRef] 
10. Ji, J.; Cai, J.Y.; Huang, W.Z.; Feng, Y. Experimental Study on the Performance of Solar-Assisted Multi-Functional Heat Pump Based on Enthalpy Difference Lab with Solar Simulator. Renew. Energy 2015, 75, 381-388. [CrossRef]

11. Omojaro, P.; Breitkopf, C. Direct Expansion Solar-Assisted Heat Pumps: A Review of Applications and Recent Research. Renew. Sustain. Energy Rev. 2013, 22, 33-45. [CrossRef]

12. Tagliafico, L.A.; Scarpa, F.; Valsuani, F. Direct Expansion Solar-Assisted Heat Pumps-A Clean Steady State Approach for Overall Performnace Analysis. Appl. Therm. Eng. 2014, 66, 216-226. [CrossRef]

13. Mohanraj, M.; Belyayev, Y.; Jayaraj, S.; Kaltayev, A. Research and Developments on Solar Assisted Compression Heat Pump Systems-A Comprehensive Review (Part A: Modeling and Modifications). Renew. Sustain. Energy Rev. 2018, 83, 90-123. [CrossRef]

14. Mohanraj, M.; Belyayev, Y.; Jayaraj, S.; Kaltayev, A. Research and Developments on Solar Assisted Compression Heat Pump Systems-A Comprehensive Review (Part B: Applications). Renew. Sustain. Energy Rev. 2018, 83, 124-155. [CrossRef]

15. Fonticiella, O.M.C.; DosReis-Parise, J.A. Estudio Estructural en Instalaciones de Bomba de Calor. Ing. Energética Apl. Ind. 2013, 34, 119-128.

16. Reyes, E.T.; de Gortari, J.C. Optimal Performance of an Irreversible Solar Assisted Heat Pump. Exergy Int. J. 2001, 1, 107-111. [CrossRef]

17. Kalogirou, S.; Karellas, S.; Braimakis, K.; Stanciu, C.; Badescu, V. Exergy Analysis of Solar Thermal Collectors and Processes. Prog. Energy Combust. Sci. 2016, 56, 106-137. [CrossRef]

18. Guo, J.J.; Wu, J.Y.; Wang, R.Z.; Li, S. Experimental Research and Operation Optimization of an Air Source Heat Pump Water Heater. Appl. Energy 2011, 88, 4128-4138. [CrossRef]

19. Sánta, R.; Garbai, L.; Fürstner, I. Optimization of a Heat Pump System. Energy 2015, 89, 45-54. [CrossRef]

20. Potočnik, P.; Vidrih, B.; Kitanovski, A.; Govekar, E. Analysis and Optimization of Thermal Comfort in Residential Buildings by means of a Weather-Controlled Air-to-Water Heat Pump. Build. Environ. 2018, 140, 68-79. [CrossRef]

21. Bell, I.H.; Lemort, V. Optimization of Vapor Compression Heat Pump for Satellite Cooling. Int. J. Refrig. 2015, 58, 69-78. [CrossRef]

22. Mehrpooya, M.; Hemmatabady, H.; Ahmadi, M.H. Optimization of Performance of Combined Solar Collector-Geothermal Heat Pump Systems to Supply Thermal Load Needed for Heating Greenhouses. Energy Convers. Manag. 2015, 97, 382-392. [CrossRef]

23. Alabdulkareem, A.; Eldeeb, R.; Hwang, Y.; Aute, V.; Radermacher, R. Testing, Simulation and Soft-Optimization of R410A low-GWP Alternatives in Heat Pump Systems. Int. J. Refrig. 2015, 60, 106-117. [CrossRef]

24. Calise, F.; D'Accadia, M.D.; Figaj, R.D.; Vanoli, L. A Novel Solar-Assisted Heat Pump Driven by Photovoltaic/Thermal Collectors: Dynamic Simulation and Thermoeconomic Optimization. Energy 2016, 95, 346-366. [CrossRef]

25. Calise, F.; D'Accadia, M.D.; Figaj, R.D.; Vanoli, L. Thermoeconomic Optimization of a Solar-Assisted Heat Pump Based on Transient Simulations and Computer Design of Experiments. Energy Convers. Manag. 2016, 125, 166-184. [CrossRef]

26. Fang, Z.S.; Feng, X.W.; Zheng, Z.M.; Zhou, X.Q.; Li, L.; Huang, Y.; Wang, H.; Liu, F.J. Experimental Study on Performance Optimization of Air Source Heat Pump using DOE Method. Exp. Heat Transf. 2019, 32, 267-283. [CrossRef]

27. Alimohammadisagvand, B.; Jokisalo, J.; Kilpeläinen, S.; Ali, M.; Sirén, K. Cost-Optimal Thermal Energy Storage System for Residential Building with Heat Pump Heating and Demand Response Control. Appl. Energy 2016, 174, 275-287. [CrossRef]

28. Li, Y.H.; Kao, W.C. Taguchi Optimization of Solar Thermal and Heat Pump Combisystems Under Five Distinct Climatic Conditions. Appl. Therm. Eng. 2018, 133, 283-297. [CrossRef]

29. Kalogirou, S. Applications of Artificial Neural Networks for Energy Systems. Appl. Energy 2000, 67, 17-35. [CrossRef]

30. Mohanraj, M.; Jayaraj, S.; Muraleedharan, C. Applications of Artificial Neural Networks for Refrigeration, Air, Conditioning and Heat Pump Systems-A Review. Renew. Sustain. Energy Rev. 2012, 16, 1340-1358. [CrossRef] 
31. Bellos, E.; Tzivanidis, C. Multi-Objective Optimization of a Solar Assisted Heat Pump-Driven by Hybrid PV. Appl. Therm. Eng. 2019, 149, 528-535. [CrossRef]

32. Khorasaninejad, E.; Hajabdollahi, H. Thermoeconomic and Environmental Optimization of Solar Assisted Heat Pump by Using Multi Objective Particle Swarm Algorithm. Energy 2014, 72, 680-690. [CrossRef]

33. Lee, S.H.; Jeon, Y.; Chung, H.J.; Cho, W.; Kim, Y. Simulation Based Optimization of Heating and Cooling Seasonal Performances of an Air-to-Air Heat Pump considering Operating and Design Parameters using Genetic Algorithm. Appl. Therm. Eng. 2018, 144, 362-370. [CrossRef]

34. Starke, A.R.; Cardemil, J.M.; Colle, S. Multi-Objective Optimization of a Solar-Assisted Heat Pump for Swimming Pool Heating using Genetic Algorithm. Appl. Therm. Eng. 2018, 142, 118-126. [CrossRef]

35. International Energy Agency. Mexico's Energy Outlook; World Energy Outlook Special Report; IEA Publications: Paris, France, 2016.

36. Secretariat of Energy. Overall Energy Balance Report 2017. Off. Fed. J. November 23rd; Office for Domestic affairs: Mexico City, Mexico, 2018. (In Spanish)

37. National Development Plan 2013-2018. Available online: https://gfmd.org/pfp/ppd/29 (accessed on 25 September 2019).

38. National Energy Transition Law DOF-24-12-2015. Available online: https://www.iea.org/policiesandmeasures/ pams/mexico/name-153753-en (accessed on 25 September 2019).

39. Secretariat of Environment and Natural Resources. Annual Report 2007-2017 Network of Atmospheric Observatories of Mexico City; Office for Domestic Affairs: Mexico City, Mexico, 2017. (In Spanish)

40. De León-Ruiz, J.E.; Carvajal-Mariscal, I. Mathematical Thermal Modelling of a Direct-Expansion Solar-Assisted Heat Pump Using Multi-Objective Optimization Based on the Energy Demand. Energies 2018, 11, 1773. [CrossRef]

41. De León-Ruiz, J.E.; Carvajal-Mariscal, I. Thermal Capacity: Additional Relative Efficiency to Assess the Overall Performance of Heat Pump-Based Heating Systems. Appl. Therm. Eng. 2019, 159, 113841. [CrossRef]

42. Kalogirou, S. Solar Energy Engineering: Processes and Systems; Elsevier Academic Press: Amsterdam, The Netherlands, 2013.

43. Fuji, T.; Imura, H. Natural Convection Heat Transfer from a Plate with Arbitrary Inclination. Int. J. Heat Mass Transf. 1972, 15, 755-767. [CrossRef]

44. Reindl, D.T.; Beckman, W.A.; Duffie, J.A. Diffuse Fraction Correlations. Sol. Energy 1990, 45, 1-7. [CrossRef]

45. Reindl, D.T.; Beckman, W.A.; Duffie, J.A. Evaluation of Hourly Tilted Surface Radiation Models. Sol. Energy 1990, 45, 9-17. [CrossRef]

46. Hollands, K.G.T.; Unny, T.E.; Raithby, G.D.; Konicek, L. Free Convective Heat Transfer Across Inclined Layers. ASME J. Heat Transf. 1976, 98, 189-193. [CrossRef]

47. Rattner, A.; Bohren, J. Heat and Mass Correlations; School of Engineering and Applied Science of the University of Pennsylvania: Philadelphia, PA, USA, 2008.

48. Chen, B.; Kasher, J.; Maloney, J.; Girgis, G.A.; Clark, D. Determination of the Clear Sky Emissivity for Use in Cool Storage and Roof Pond Applications; Passive Solar Research Group of the University of Nebraska at Omaha: Omaha, NE, USA, 1995.

49. Berdahl, P.; Fromberg, R. The Thermal Radiance of Clear Skies. Sol. Energy 1982, 29, 299-314. [CrossRef]

50. Moran, M.J.; Shapiro, H.N. Fundamentals of Engineering Thermodynamics; John Wiley \& Sons: Hoboken, NJ, USA, 2006.

51. Wark, K.; Richards, D.E. Thermodynamics; McGraw-Hill: New York, NY, USA, 1999.

52. Active National Geodesic Network. International Terrestrial Reference Frame Coordinates; National Institute of Geography and Statistics: Mexico City, Mexico, 2018. (In Spanish)

53. Nadaraya, E.A. On Estimating Regression. Theory Probab. Appl. 1964, 9, 141-142. [CrossRef]

54. Parzen, E. On Estimation of Probability Density Function and the Mode. Ann. Math. Stat. 1962, 33, $1065-1076$. [CrossRef]

55. Silverman, B.W. Density Estimation for Statistics and Data Analysis, 1st ed.; Monographs on Statistics and Applied Probability; Chapman \& Hall: London, UK, 1986.

56. Najim, K. Stochastic Processes: Estimation, Optimization and Analysis; Kogan Page Science: London, UK, 2004.

57. Gramacki, A. Nonparametric Kernel Density Estimation and Its Computational Aspects; Studies in Big Data; Springer International Publishing AG: Cham, Switzerland, 2018. 
58. García-Gutiérrez, A.; Barragán-Reyes, R.M.; Arellano-Gómez, V.M. Research on Heat Pumps in Mexico Operating on Waste Energy as Heat Source. In Proceedings of the Geothermal Resources Council Annual Meeting, 30 September-3 October 2007; Geothermal Resources Council: Reno, NV, USA.

59. Charbonneau, P.; Knapp, B. PIKAIA; National Center for Atmospheric Research-High Altitude Observatory: Boulder, CO, USA, 2002.

60. Eiben, A.E.; Smith, J.E. Introduction to Evolutionary Computing; Springer: Berlin/Heidelberg, Germany; New York, NY, USA, 2003.

61. Global Optimization Algorithms Theory and Applications. Available online: http://www.it-weise.de/ (accessed on 25 September 2019).

62. Sivanandam, S.N.; Deepa, S.N. Introduction to Genetic Algorithms; Springer: Berlin/Heidelberg, Germany; New York, NY, USA, 2008.

(C) 2019 by the authors. Licensee MDPI, Basel, Switzerland. This article is an open access article distributed under the terms and conditions of the Creative Commons Attribution (CC BY) license (http://creativecommons.org/licenses/by/4.0/). 